\title{
Importin $\alpha 7$ deficiency causes infertility in male mice by disrupting spermatogenesis
}

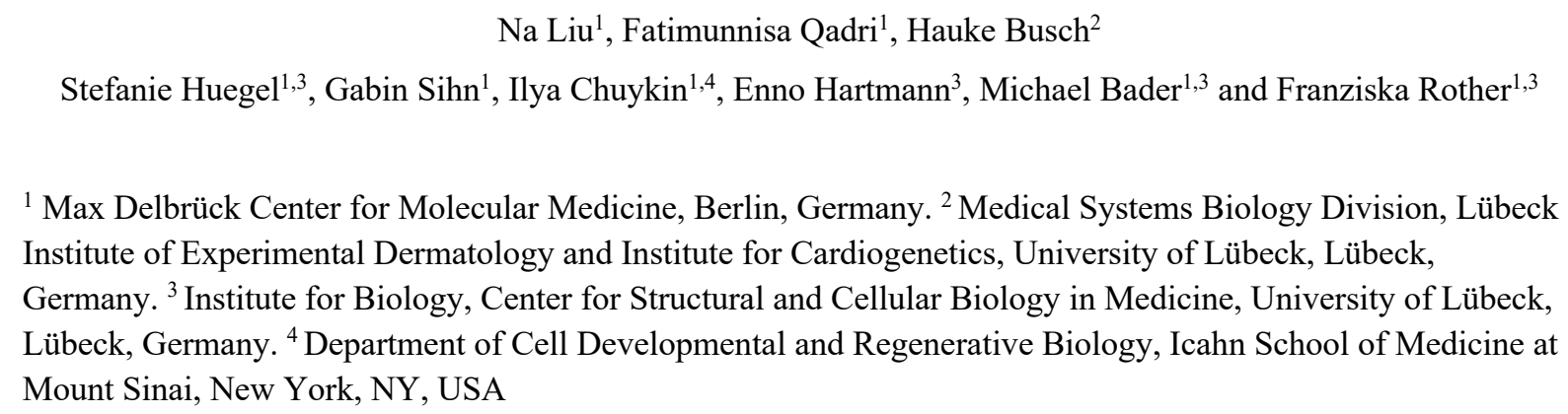

Corresponding author: Franziska Rother (franziska.rother@mdc-berlin.de)

Running title: Importin $\alpha 7$ in spermatogenesis

Keywords: importin, karyopherin, spermatogenesis, male fertility, testis

\section{Summary statement}

Using two different mouse models, we delineate the morphological and functional impact of importin $\alpha 7$ on spermatogenesis and Sertoli cell function and show that this protein is crucial for fertility in male mice.

\section{Abstract}

Spermatogenesis is driven by an ordered series of events, which rely on trafficking of specific proteins between nucleus and cytoplasm. The importin $\alpha$ family of proteins mediates movement of specific cargo proteins when bound to importin $\beta$. Importin $\alpha$ genes have distinct expression patterns in mouse testis, implying they may have unique roles during mammalian spermatogenesis. Here we use a loss-of-function approach to specifically determine the role of importin $\alpha 7$ in spermatogenesis and male fertility. We show that ablation of importin $\alpha 7$ in male mice leads to infertility and has multiple cumulative effects on both germ cells and Sertoli cells. Importin $\alpha 7$-deficient mice exhibit an impaired Sertoli cell function, including loss of Sertoli cells and a compromised nuclear transport of the androgen receptor. Furthermore, our data demonstrate devastating defects in spermiogenesis that are accompanied by disturbed histoneprotamine-exchange, absence of the transcriptional regulator Brwd1 and altered expression of 
Rfx2 target genes, resulting in incomplete sperm maturation and massive loss of sperms. Our work uncovers the essential role of importin $\alpha 7$ in spermatogenesis and hence in male fertility.

\section{Introduction}

The best characterized mechanism of nuclear import of molecules consists of importin $\alpha$ and importin $\beta$ heterodimers. Importin $\alpha$ proteins are comprised of three main structural domains: a $\mathrm{N}$-terminal region which is the importin $\beta$ binding (IBB) domain; a central domain containing Armadillo (ARM) motifs; and a weakly conserved C-terminal region. The central domain of importin $\alpha$ binds Nuclear Localization Signals (NLSs) that are present in the target cargo proteins. Upon cargo binding, importin $\alpha$ binds to importin $\beta$ via its IBB domain forming a trimeric transport complex, which is then translocated into the nucleus via importin $\beta$ interactions with nucleoporins (Nups) lining the nuclear pore complex (Macara, 2001; Miyamoto et al., 2012). To date, three importin $\alpha$ subtypes have been identified in C. elegans and D. melanogaster, while up to seven importin $\alpha$ isoforms have been found in mammals (Kohler et al., 1997; Tejomurtula et al., 2009; Tsuji et al., 1997).

Male reproductive function relies on normal spermatogenesis within the seminiferous epithelium of the testis. During spermatogenesis, the spermatogonia undergo mitosis and differentiate into primary spermatocytes. The primary spermatocytes process through preleptotene, leptotene, zygotene, pachytene, and diplotene stages of meiosis I to generate secondary spermatocytes. Subsequently, the secondary spermatocytes enter the second meiotic division resulting in round spermatids. The haploid round spermatids undergo dramatic morphological changes, and finally differentiate into mature spermatozoa (Russell, 1990).

Sertoli cells are the supporting somatic cells essential for the development of male germ cells of all stages. It has been shown that the number and function of Sertoli cells determine testicular size, germ cell numbers and spermatozoa output (Orth et al., 1988). Sertoli cell functions include (i) providing structural support and nutrition to developing germ cells, (Chihara et al., 2013) simultaneous support of synchronous differentiation among several cohorts of germ cells of differing maturity, (iii) secretion of seminiferous fluid, (iv) phagocytosis of degenerating germ cells and residual bodies and (v) release of spermatids at spermiation (Bellve and Zheng, 1989; Chihara et al., 2013; Clermont, 1993; Russell and Griswold, 1993).

A key feature of Sertoli cell structural support for developing germ cells is the blood-testis barrier (BTB) that resides in tight junctions located between adjacent Sertoli cells (Johnson et al., 2008). At the beginning of meiosis preleptotene spermatocytes 'pass through' the BTB. Once the germ cells move beyond the BTB and the BTB reforms behind them, the germ cells 
no longer have access to serum factors and they become totally dependent upon Sertoli cells to supply nutrients and growth factors (Walker, 2010). This structural arrangement creates an immunologic barrier by isolating the more advanced germ cell types from the immune system so that their antigens do not stimulate autoimmunity (Johnson et al., 2008; Orth et al., 1988). The successful completion of spermatogenesis is dependent on successive division and differentiation steps, which require multiple changes in gene expression; coordinated by a plethora of transcription and other factors expressed within the testis (Eddy and O'Brien, 1998; Hermo et al., 2010). The access of these factors to the nucleus where they can exert their function, is tightly regulated for these proteins, and it has been postulated that germ cell differentiation is controlled by nucleocytoplasmic transport events (Major et al., 2011). In fact, the mRNAs of different importin $\alpha$ isoforms and of importin $\beta$ are all expressed in spermatogonia, spermatocytes, round spermatids and Sertoli cells (Major et al., 2011; Shima et al., 2004), which raises the possibility that the importin $\alpha / \beta$ mediated nuclear import pathway is involved in the regulation of spermatogenesis and Sertoli cell function. However, a specific role of a single importin $\alpha$ isoform in spermatogenesis and male reproduction has not been determined yet.

We have previously shown that in importin $\alpha 7$-deficient mothers, embryonic development stops at the two-cell stage due to a severely disturbed zygotic genome activation, therefore importin $\alpha 7$ is essential for early embryonic development in mice (Rother et al., 2011). In this report, we show that ablation of Kpna6, the gene encoding for importin $\alpha 7$, results in a critical defect in spermatogenesis in male mice. We demonstrate that importin $\alpha 7$ protein is expressed in the nuclei of round spermatids, elongating spermatids and Sertoli cells. Consistent with this pattern, importin $\alpha 7$ deficiency results in multiple defects in both germ cells and Sertoli cells culminating in oligozoospermia. Our results demonstrate an essential role for importin $\alpha 7$ in male fertility by regulating spermiogenesis and Sertoli cell function.

\section{Results}

\section{Importin $\alpha 7$ is essential for male fertility}

To investigate the physiological role of mammalian importin $\alpha$, we have generated two mouse lines with targeted disruption of importin $\alpha 7$. In one line, exon 2 of the importin $\alpha 7$ gene is deleted which, due to unexpected alternative splicing, results in a shortened mRNA containing a cryptic translational start site in exon 3 and thus leading to synthesis of a truncated protein lacking the importin $\beta$ binding domain $\left(\alpha 7^{\triangle \mathrm{IBB} / \Delta \mathrm{IBB}}\right.$, Fig. 1A). In the other line a gene trap cassette is located in intron 1 of the importin $\alpha 7$ gene resulting in a complete loss of the protein 
$103\left(\alpha 7^{-/}\right.$, Fig. 1A). Female mice of both lines are infertile (Rother et al., 2011). Most interestingly, the male $\alpha 7^{-/-}$mice are fertile, while $\alpha 7^{\mathrm{AIBB} / \Delta \mathrm{IBB}}$ males were found to be sterile, although they were sexually active and produced vaginal plugs in female partners (data not shown). We observed that, although importin $\alpha 7$ protein is disrupted in all other organs of $\alpha 7^{-/-}$males (Rother et al., 2011), full-length importin $\alpha 7$ protein is still expressed in the testis, albeit to a lower extent, whereas it is completely absent from $\alpha 7^{\Delta \mathrm{IBB} / \Delta \mathrm{IBB}}$ testes (Fig. 1B). The reason for the exclusive expression of importin $\alpha 7$ in the testis of importin $\alpha 7^{-/-}$males is that an alternative promoter and exon 1 (exon 1A) are used which are located downstream of the gene trap cassette (Fig. 1A-C, EST accession number BY353738.1). On the contrary, only a truncated non-

112 functional importin $\alpha 7$ is existent in the $\alpha 7^{\Delta \mathrm{IBB} / \Delta \mathrm{IBB}}$ testes (Fig. 1B), which leads to male 113 infertility, suggesting that importin $\alpha 7$ plays an important role in mouse testis, and is essential 114 for male fertility.

Disruption of importin $\alpha 7$ gene causes growth retardation, reduced testis size and severe oligozoospermia

118 Importin $\alpha 7^{\mathrm{\triangle IBB} / \Delta \mathrm{IBB}}$ mice and $\alpha 7^{-/-}$mice were born at a lower frequency $\left(\alpha 7^{\mathrm{AIBB} / \Delta \mathrm{IBB}}: 18.8 \%\right.$, $\left.\mathrm{n}=739 ; \mathrm{p}<0.0001 ; \alpha 7^{-/}: 16 \%, \mathrm{n}=214, \mathrm{p}=0.0015\right)$ than predicted by Mendelian laws. With regards to growth and development, the heterozygous males are indistinguishable from wildtype (WT) males (data not shown). However, $\alpha 7^{\Delta \mathrm{IBB} / \Delta \mathrm{IBB}}$ pups that survived the gestation period displayed severe growth retardation in the postnatal phase, and this growth defect persisted until adult life (Fig. 1D). Male importin $\alpha 7^{-/-}$mice also displayed a significant growth retardation, albeit the effect in young mice was stronger in $\alpha 7^{\Delta \mathrm{IBB} / \Delta \mathrm{IBB}}$ mice. At the age of 16 weeks, males of both mutant lines showed the same reduction in body weight compared to WT males (Fig. 1D). Testes of adult $\alpha 7^{\triangle \mathrm{IBB} / \Delta \mathrm{IBB}}$ mice exhibited a pronounced reduction both in size and weight, and the testicular weight to body weight ratio was reduced by $40 \%$ at the age of 8 10 weeks compared to WT controls and to $\alpha 7^{-/-}$mice, which displayed a normal relative testis weight and size (Fig. 1E). Plasma testosterone levels were unchanged (data not shown).

130 Histological analyses of testes revealed that spermatogenesis was drastically altered in importin $131 \alpha 7^{\mathrm{\Delta IBB} / \Delta \mathrm{IBB}}$ while no major changes were detected in importin $\alpha 7^{-/-}$compared to WT testes (Fig.

132 2A). Seminiferous tubules in the importin $\alpha 7^{\triangle \mathrm{IBB} / \Delta \mathrm{IBB}}$ testes were smaller in diameter than those 133 in WT and importin $\alpha 7^{-/-}$mice (Fig. 2A and C). The number of germ cells was reduced, and 134 they were disorganized in the tubular epithelium. Moreover, mature spermatozoa were rarely 135 found in the lumen of $\alpha 7^{\Delta \mathrm{IBB} / \Delta \mathrm{IBB}}$ seminiferous tubules and multinucleated spermatid giant cells 136 were frequently observed (Fig. 2A). There were very few spermatozoa in the caput of the 
$\alpha 7^{\mathrm{AIBB} / \mathrm{ABB}}$ epididymides, and spermatozoa were hardly detectable in the caudal epididymides by H\&E staining (Fig. 2B). Additionally, sloughed germ cells, and germ cell debris were commonly observed in the corpus epididymal lumen of $\alpha 7^{\Delta \mathrm{IBB} / \Delta \mathrm{IBB}}$ males (Fig. 2B). The total epididymal sperm number in $\alpha 7^{\mathrm{AIBB} / \triangle \mathrm{IBB}}$ was only $3 \%$ of those of WT males (Fig. $2 \mathrm{D} ; 0.8 \times 10^{6}$ versus $25.6 \times 10^{6}$ ), moreover, almost all of the residual sperms found in the $\alpha 7^{\mathrm{AIBB} / \Delta \mathrm{IBB}}$ epididymides displayed abnormal heads in contrast to $\alpha 7^{-/-}$and WT sperms (Fig. 2E).

143 Surprisingly, also importin $\alpha 7^{-/-}$sperm count was significantly reduced, suggesting a partially 144 reduced fertility in these mice (Fig. 2D). In both lines the epididymal sperm count of heterozygous mice was normal (Fig. S1A).

\section{Importin $\alpha 7$ expression pattern in mouse testis}

148 To assess the cell type-specific function of importin $\alpha 7$ in the testis, we performed 149 immunohistochemistry for importin $\alpha 7$ in WT mice using an antibody which detects the C150 terminus and thereby the full length as well as the truncated form of importin $\alpha 7$ (Fig. 3). No 151 importin $\alpha 7$ protein could be detected in spermatogonia and meiotic spermatocytes. Early round spermatids (step 1) showed very low levels of expression which increased throughout the development of round spermatids (stages I-VIII), reaching its highest expression in step 9 elongating spermatids (stage IX), where importin $\alpha 7$ displayed a high nuclear and low cytoplasmic expression. With the onset of nuclear elongation, localization of importin $\alpha 7$ shifted to the cytoplasm, and was no longer detectable after the residual bodies were removed in step 16 sperms (stage VII-VIII). Importin $\alpha 7$ was not detected in peritubular myoid cells and displayed a low nuclear expression in some of the Leydig cells, however it is highly expressed in the nuclei of Sertoli cells in all stages of the seminiferous epithelium (Fig. 3). The massive increase of importin $\alpha 7$ expression in step 9 elongating spermatids, and the high expression level in the nuclei of Sertoli cells suggest an important role of importin $\alpha 7$ in these cells. As the antibody against the C-terminus of importin $\alpha 7$ also detects the truncated form of the protein, it showed a regular staining in $\alpha 7^{\Delta \mathrm{IBB} / \Delta \mathrm{IBB}}$ testes, while testis sections of importin $\alpha 7^{-/-}$ mice that express importin $\alpha 7$ exclusively in the testes revealed that the protein expression is rescued in germ cells, but not in Sertoli cells in this mouse line (Fig. 4A). To verify these results, we generated an antibody against the N-terminus of importin $\alpha 7$ that could discriminate between the full-length and the truncated $\triangle \mathrm{IBB}$-protein in which the $\mathrm{N}$-terminus is missing

168 (Fig. 1A). Staining of testis sections of WT mice showed a robust signal in round and elongating 169 spermatids as well as Sertoli cells. In contrast, no signals could be detected in $\alpha 7^{\Delta \mathrm{IBB} / \Delta \mathrm{IBB}}$ testis sections with this antibody, confirming the truncation of importin $\alpha 7$ in these mice (Fig. 4B). 
171 In importin $\alpha 7^{-/-}$testes, the rescued expression in developing spermatids could be verified, while 172 no expression was found in Sertoli cells (Fig. 4B).

173 A detailed analysis of the localization of the rescued importin $\alpha 7$ in importin $\alpha 7^{-/-}$testes using 174 the C-terminal antibody revealed that the expression of the protein in germ cells is comparable 175 with WT testis, with low levels in round spermatids step 1 (stage I) and gradual increase up to 176 step 8 (stage VIII) reaching the highest level in step 9-11 elongating spermatids. In condensing 177 spermatids (step 12) localization of importin $\alpha 7$ shifted to the cytoplasm as it was the case in 178 WT mice, and was no longer detectable after the residual bodies were removed in step 16 spermatids (Fig. 4A, data not shown). We also confirmed the earlier observation that Sertoli cells of $\alpha 7^{-/-}$testes do not express importin $\alpha 7$ protein, suggesting that the expression of the 181 protein is solely rescued in germ cells. The missing expression of importin $\alpha 7$ in Sertoli cells 182 could thus account for the reduced sperm cell number observed in importin $\alpha 7^{-/-}$mice, however, 183 only importin $\alpha 7^{\mathrm{AIBB} / \triangle \mathrm{IBB}}$ mice are infertile, suggesting, that the expression of the protein in 184 germ cells is indispensable for normal sperm development and fertility.

185 Thus, importin $\alpha 7^{-/-}$mice express a mild Sertoli cell related phenotype, while importin $\alpha 7^{\mathrm{ABB} / \Delta \mathrm{IBB}}$ mice express a mixed phenotype consisting of Sertoli cell related and germ cell related defects. The infertile importin $\alpha 7^{\Delta \mathrm{IBB} / \Delta \mathrm{IBB}}$ mice express a truncated importin $\alpha 7$ protein in Sertoli cells and in the developing sperms. On the other hand, the heterozygous importin $\alpha 7^{\mathrm{LBB} /+}$ mice express the full-length plus the truncated protein in Sertoli cells and in the developing sperms, however, sperm count in these mice turned out to be completely normal (Fig. S1A), excluding a dominant negative effect of the truncated protein on sperm count.

192 Nevertheless, to discriminate between Sertoli cell-related phenotype and sperm cell-related phenotype, we compared mice of both lines ( $\alpha 7^{\mathrm{\Delta IBB} / \Delta \mathrm{IBB}}$ mice vs. $\alpha 7^{-/-}$mice). To rescue the germ cell phenotype without rescuing the Sertoli cell phenotype in importin $\alpha 7^{\Delta \mathrm{IBB} / \Delta \mathrm{IBB}}$ mice, we crossed importin $\alpha 7^{\mathrm{\Delta IBB} / \Delta \mathrm{IBB}}$ and $\alpha 7^{-/-}$mice. The resulting compound heterozygous importin

$196 \alpha 7^{\Delta \mathrm{IBB} /-}$ mice express only the truncated importin $\alpha 7$ in Sertoli cells and truncated plus full197 length importin $\alpha 7$ in developing sperms (Fig. S1B). Epididymal sperm count revealed a 198 significant increase of sperm number in importin $\alpha 7^{\Delta \mathrm{IBB} /-}$ mice compared to importin $\alpha 7^{\Delta \mathrm{IBB} / \Delta \mathrm{IBB}}$ 199 mice (Fig. S1A), suggesting that, indeed, the addition of full-length importin $\alpha 7$ in developing 200 sperms can partially rescue the oligozoospermia. However, the sperm count was still markedly 201 lower than in WT mice and the values were comparable to importin $\alpha 7^{-/-}$mice, confirming that 202 the absence of full-length importin $\alpha 7$ in Sertoli cells is the reason for the partial reduction in 203 sperm count. Thus, we can conclude that importin $\alpha 7$ expression in spermatocytes and round 204 spermatids is essential for normal sperm development and fertility. 


\section{Importin $\alpha 7$ deficiency leads to defects in Sertoli cells}

207 Since importin $\alpha 7$ was intensively expressed in the nuclei of WT Sertoli cells (Fig. 3), the protein may be essential for the function of these cells. We observed a reduced number of Sertoli cells in testes of adult $\alpha 7^{\mathrm{\triangle IBB} / \Delta \mathrm{IBB}}$ mice and $\alpha 7^{-/-}$mice, suggesting that importin $\alpha 7$ perturbation caused a loss of Sertoli cells (Fig. 5A, wt=14.54/tubule; $\alpha 7^{\Delta \mathrm{IBB} / \Delta \mathrm{IBB}}=11.89 /$ tubule; $\alpha 7^{-/-}$ $=11.39 /$ tubule). Moreover, in both mutant lines Sertoli cells were frequently observed being detached in the middle of seminiferous tubules and the epididymal lumen (Fig. 5B). The androgen receptor (AR), which is highly expressed in Sertoli cells, plays an important role in spermatogenesis. By immunohistochemistry we observed pronounced defects of AR nuclear import in Sertoli cells of both mutant lines (Fig. 5C). However, quantification of AR mRNA expression as well as protein levels in testes did not reveal any differences (data not shown). Thus, ablation of importin $\alpha 7$ in Sertoli cells is accompanied by AR nuclear import deficiency. To test, whether expression of AR-related or Sertoli cell-specific genes is affected in importin $\alpha 7^{\mathrm{AIBB} / \Delta \mathrm{IBB}}$ and importin $\alpha 7^{-/-}$mice, we analyzed the expression levels of AR-regulated genes such as rhox5, pem, wt1, clusterin, gatal, cldn3, and cldn11. No significant differences in mRNA levels were detected for most of these genes. Only cldn3 expression was markedly downregulated in importin $\alpha 7^{\mathrm{\Delta IBB} / \Delta \mathrm{IBB}}$, but not in $\alpha 7^{-/-}$testes (Fig. 5D). To confirm these results, immunostaining of testis sections for Cldn 3 was performed, revealing the specific localization in basal tight junctions of late stage VIII tubuli in both mutant mouse lines (Fig. 5E). Tight junctions are a major component of the blood-testis-barrier (BTB) located between adjacent Sertoli cells. To further analyze possible defects in tight junction formation of Sertoli cells, we performed immunostaining for ZO-1, a specific tight junction protein, in testis sections. No differences were found in the expression and localization of ZO-1 in basal tight junctions and apical ectoplasmic specializations of stage IV-VI tubules (Fig. 6A). We evaluated the functional integrity of the BTB by incubating testicular protein extracts from two months old WT mice with sera taken from either WT, importin $\alpha 7^{\Delta \mathrm{IBB} / \Delta \mathrm{IBB}}$ or importin $\alpha 7^{-/-}$mice at 8,16 and 20 weeks of age. A subsequent western blot analysis revealed in some, but not in all cases, differences in the protein band pattern with additional bands appearing in importin $\alpha 7^{\Delta \mathrm{IBB} / \Delta \mathrm{IBB}}$

234 and importin $\alpha 7^{-/-}$mice. Thus, the immunological barrier may be leaky and therefore antibodies against testicular antigens are occasionally present in both mutant lines (Fig. 6B). However, a

236 subsequent analysis of the presence of immunoglobulins within testicular tissue in mice of 
the BTB is not severely impaired. Moreover, by injection of biotin into the testis we could not find a compromised BTB in importin $\alpha 7^{\mathrm{\Delta IBB} / \Delta \mathrm{IBB}}$ and importin $\alpha 7^{-/-}$mice (Fig. 6D).

240 Further analysis of Sertoli cell cytoskeletal proteins revealed an abnormal localization of the 241 intermediate filament vimentin in Sertoli cells of importin $\alpha 7^{\Delta \mathrm{IBB} / \Delta \mathrm{IBB}}$ and importin $\alpha 7^{-/-}$mice.

242 Vimentin-based filaments no longer stretched across the Sertoli cell cytosol but retracted from 243 the cell cortical region and were wrapped around the cell nuclei (Fig. 6E). In contrast, beta-III 244 tubulin organization was not perturbed in Sertoli cells of importin $\alpha 7^{\mathrm{\Delta IBB} / \Delta \mathrm{IBB}}$ and importin $\alpha 7^{-}$

$245 /$ mice (data not shown), suggesting that there is no general effect on Sertoli cell morphology 246 but rather a specific change in vimentin distribution.

247 The compromised Sertoli cells lead to defects in sperm orientation in both importin $\alpha 7^{\mathrm{AIBB} / \Delta \mathrm{IBB}}$ 248 and importin $\alpha 7^{-/-}$mice. (Fig. 6F). Interestingly, sperm transport through the seminiferous 249 epithelium, which is also dependent on Sertoli cells, was severely disturbed in importin $250 \alpha 7^{\mathrm{AIBB} / \Delta \mathrm{IBB}}$ mice, but was found to be unaffected in importin $\alpha 7^{-/-}$mice (Fig. 6G). In WT testis, 251 only one generation of spermatids was found in stages IX-XII, during the transition from round 252 into elongating spermatids. However, two generations of spermatids were often observed in 253 stages IX-XII in importin $\alpha 7^{\mathrm{\triangle IBB} / \Delta \mathrm{IBB}}$ mice (Fig. $6 \mathrm{H}$ ). The additionally found spermatids were 254 more mature with more condensed nuclei, which implicates that they were not released from 255 Sertoli cells in the previous spermatogenesis cycle. Although correct spermiation is dependent on Sertoli cells, we could not detect residual sperms in stage IX-XII seminiferous tubules of 258 only.

Importin $\alpha 7$ deficiency-related loss of spermatocytes starts with leptotene/zygotene transition

262 To elucidate the start of germ cell loss during spermatogenesis in testes deficient for importin $\alpha 7$, we quantitatively evaluated different developmental steps of spermatogenesis. By labelling of spermatogonia with the pluripotency marker Sall4, no differences between genotypes were detected, excluding a severe loss of spermatogonia (Fig. 7A). In the adult testis the BrdUpositive cells in stages VII-VIII are preleptotene spermatocytes (Zhou et al., 2008). We observed that the number of BrdU-labeled preleptotene spermatocytes per tubule in importin $\alpha 7^{\mathrm{AIBB} / \Delta \mathrm{IBB}}$ and $\alpha 7^{-/-}$testes were similar to those in WT mice (Fig. 7A), indicating that importin $\alpha 7$ is dispensable for the development of preleptotene spermatocytes. We next tested for $\gamma \mathrm{H} 2 \mathrm{AX}$, a phosphorylated form of histone 2AX, that exhibits an intense diffuse staining pattern in spermatocytes at the leptotene/zygotene transition in stages X-XI, and exclusively localizes 
to the sex chromosomes (so called sex body) within pachytene spermatocytes (Blanco-

273 Rodriguez, 2009; Celeste et al., 2002; Peters et al., 1997). In adult importin $\alpha 7^{\Delta \mathrm{IBB} / \Delta \mathrm{IBB}}$ testes

274 and importin $\alpha 7^{-/-}$testes, the numbers of leptotene/zygotene spermatocytes in stages X-XI

275 decreased markedly compared to WT controls while we did not observe differences in the stage-

276 specific appearance of $\gamma \mathrm{H} 2 \mathrm{AX}$-positive chromatin (Fig. 7A, B). Interestingly, we detected a

277 further decrease in the number of stage I-VIII pachytene spermatocytes in importin $\alpha 7^{\mathrm{\Delta IBB} / \Delta \mathrm{IBB}}$

278 but not in importin $\alpha 7^{-/-}$testes showing that importin $\alpha 7^{\triangle \mathrm{IBB} / \Delta \mathrm{IBB}}$ testes were more affected than

279 importin $\alpha 7^{-/-}$testes (Fig. 7A). The ratios of pachytene to leptotene spermatocytes were similar

280 in WT and importin $\alpha 7^{-/-}$testes, while it was markedly reduced in importin $\alpha 7^{\mathrm{ABB} / \Delta \mathrm{IBB}}$ mice (wt:

$\left.2810.94 ; \alpha 7^{\mathrm{ABB} / \Delta \mathrm{IBB}}: 0.77, \alpha 7^{-/ \cdot}: 1.00\right)$, suggesting that development of pachytene spermatocytes is

282 dependent on importin $\alpha 7$. The reduced numbers of step 1-8 round spermatids in importin

$283 \alpha 7^{\triangle \mathrm{IBB} / \Delta \mathrm{IBB}}$ and importin $\alpha 7^{-/-}$testes were comparable with numbers of pachytene spermatocytes

284 (Fig. 7A), while the ratios of round spermatids to pachytene spermatocytes were similar 285 between WT (2.6), $\alpha 7^{\mathrm{AIBB} / \Delta \mathrm{IBB}}$ (3.3) and $\alpha 7^{-/-}$testes (3.2). These observations suggest that 286 deficiency of importin $\alpha 7$ leads to a reduction in leptotene/zygotene spermatocytes, and to a 287 further decrease in pachytene spermatocytes, but surviving spermatocytes could differentiate 288 into round spermatids.

\section{Onset of spermatogenesis is delayed in importin $\alpha 7^{\mathrm{IIBB} / \Delta \mathrm{IBB}}$ mice}

291 By H\&E staining of testes from 6 weeks old mice we discovered a delayed onset of the first 292 wave of spermatogenesis: while WT and importin $\alpha 7^{-/-}$mice showed a regular histology with seminiferous tubules at various stages, in importin $\alpha 7^{\mathrm{\triangle IBB} / \Delta \mathrm{IBB}}$ mice, all tubuli displayed uniformly the same developmental stage and no round spermatids or later stages could be detected, indicating that the first meiotic wave had not been completed (Fig. 8A). We investigated this further with $\mathrm{BrdU} / \gamma \mathrm{H} 2 \mathrm{AX}$ co-labeling in day 14 mouse testes. Since $\mathrm{BrdU}$ labels mitotic spermatogonia and preleptotene spermatocytes (Zhou et al., 2008) and, $\gamma \mathrm{H} 2 \mathrm{AX}$ stains B-type spermatogonia and preleptotene spermatocytes (Blanco-Rodriguez, 2009; Hamer et al., 2003), the double-stained germ cells should be B-type spermatogonia and preleptotene spermatocytes. We observed early pachytene spermatocytes $(\gamma \mathrm{H} 2 \mathrm{AX}$ confined to the sex chromosomes) in many tubules of WT testes, while very few tubules contained early pachytene spermatocytes in $\alpha 7^{\mathrm{\triangle IBB} / \triangle \mathrm{IBB}}$ mice (Fig. 8B). In WT testes, we found only few double-stained

303 preleptotene spermatocytes; in contrast many preleptotene spermatocytes showed up in the $304 \alpha 7^{\triangle \mathrm{IBB} / \Delta \mathrm{IBB}}$ tubules. These observations suggested that in day 14 testes, most of the WT germ 305 cells already had passed through the preleptotene spermatocyte stage, and many of them 
progressed into early pachytene spermatocyte stage, however most of the mutant germ cells remained at preleptotene spermatocyte stage, with only few of them reaching pachytene stage (Fig. 8B). Analysis of day 21 testes by $\gamma \mathrm{H} 2 \mathrm{AX}$ labelling revealed a high number of leptotene/zygotene spermatocytes in importin $\alpha 7^{\mathrm{AIBB} / \Delta \mathrm{IBB}}$ mice, while in WT testes most of the spermatocytes had already reached pachytene stage and round spermatids start to be present (Fig. 8C). Together, these data suggest that, compared with WT mice, the onset of the first wave of spermatogenesis is markedly delayed in $\alpha 7^{\mathrm{AIBB} / \Delta \mathrm{IBB}}$ mice.

\section{Gene expression changes in importin $\alpha 7^{\Delta \mathrm{IBB} / \Delta \mathrm{IBB}}$ testis}

315 To obtain a transcriptome-wide insight into the affected transcripts, pathways and upstream 316 regulators after Kpna6 depletion, we performed an RNAseq analysis on whole testes of WT, 317 importin $\alpha 7^{\mathrm{\Delta IBB} / \Delta \mathrm{IBB}}$ and $\alpha 7^{-/-}$mice in triplicate. A principal component analysis on the gene 318 aggregated transcript per million values depicts the transcriptome of the importin $\alpha 7^{\mathrm{AIBB} / \triangle \mathrm{IBB}}$ 319 relative to the WT and the importin $\alpha 7^{-/-}$mice (Fig. S2). According to the PCA the transcriptomes of the former differ the most from the latter two along the first principal component (PC1), which is in accordance with the much more severe phenotype observed in importin $\alpha 7^{\mathrm{\triangle IBB} / \triangle \mathrm{IBB}}$ compared to importin $\alpha 7^{-/-}$mice. A log likelihood test between the importin $\alpha 7^{\mathrm{AIBB} / \Delta \mathrm{IBB}}$ and the WT transcriptome revealed 112 significantly regulated genes (p-value < 0.01; absolute effect size $>1$ ), with Kpna6 significantly downregulated in the former (p-value: $3^{*} 10^{-5}$; effect size: -1.51 ) (Fig. 9A; Table S3). Contrary to this and in line with the mild phenotype and the PCA, we found only 20 differentially regulated genes between WT and importin $\alpha 7^{-/-}$mice (p-value $<0.01$; absolute effect size $>1$ ), with Kpna6 showing no significance in differential expression. Therefore, we concentrated our analyses on the comparison of importin $\alpha 7^{\triangle \mathrm{IBB} / \Delta \mathrm{IBB}}$ and WT testes. We next performed a gene set analysis based on the gene effect size differences between the WT and importin $\alpha 7^{\Delta \mathrm{IBB} / \Delta \mathrm{IBB}}$ condition using the biological processes from the Gene Ontology (GO). Upregulated GO terms in importin $\alpha 7^{\mathrm{AIBB} / \Delta \mathrm{IBB}}$ are related to cell migration, extracellular matrix and development processes, while cilia, flagellum and sperm related terms are downregulated due to the dysfunctional Kpna6 gene (Fig 9B). To obtain an insight into the upstream transcription factors driving the respective gene expression, we tested the mouse regulon data from the DoroTheA library against the WT and importin $\alpha 7^{\mathrm{\triangle IBB} / \Delta \mathrm{IBB}}$ condition. In total there were 16 (20) transcription factors (TF) whose putative activity was significantly up- (down-) regulated in the importin $\alpha 7^{\Delta \mathrm{IBB} / \Delta \mathrm{IBB}}$ mice (Fig. 9C). While the upregulated TF were related to TNF-alpha signaling via NF-kB (adj. pvalue $=0.0008$ ) and TGF-beta signaling (adj. $\mathrm{p}$-value $=0.02$ ), $\mathrm{Rf} 2$, a key regulator of mouse 
spermiogenesis was downregulated. To further test the prediction, we compared the differential gene regulation from our importin $\alpha 7^{\mathrm{\triangle IBB} / \Delta \mathrm{IBB}}$ mice with testicular transcriptomes of $\mathrm{Rfx} 2$ knockout mice (GEO ID GSE68283)(Wu et al., 2016). The effect size and the direction of differential gene regulation for $\mathrm{Rfx} 2$ knockout and $\alpha 7^{\mathrm{AIBB} / \Delta \mathrm{IBB}}$ mice relative to the wild type conditions are significantly correlated according to Spearman's rho statistic (p-value $<2.2 * 10^{-}$ ${ }^{16}$ ). While both mouse lines share few upregulated genes ( $10 \%$ of Rxf2 KO; $7 \%$ of Kpna6 KO), $40 \%$ of the genes that were downregulated in Kpna6 KO, were also downregulated in Rfx2 KO (Fig. 9D, Table S4). Among the commonly downregulated genes are various proteases of the ADAM family, which are known to be involved in sperm function (Cho, 2005). A GSEA of the downregulated pathways in Rfx2 knockout and $\alpha 7^{\Delta \mathrm{IBB} / \Delta \mathrm{IBB}}$ mice depicted similar effects on cilium, its assembly, microtubule- and sperm motility-related processes (Fig.9E, Table S5). Pathways that are significantly downregulated in importin $\alpha 7^{\Delta \mathrm{IBB} / \Delta \mathrm{IBB}}$ mice (p-value $<0.05$ ), but not in Rfx2 KO mice ( $\mathrm{p}$-value $>0.1$ ) include chemical synaptic transmission, pyroptosis, sperm principal piece and acrosomal vesicle and hydrolase activity.

Downregulation of protamines and transition proteins in round spermatids and impaired histone-protamine exchange in importin $\alpha 7^{\mathrm{AIBB} / \Delta \mathrm{IBB}}$ mice

Since analysis of the altered gene expression in importin $\alpha 7^{\mathrm{AIBB} / \Delta \mathrm{IBB}}$ mice suggested the strongest impact on postmeiotic events, we performed a detailed microscopic study of sperm maturation in the testis. While spermatid elongation started regularly in stage IX seminiferous tubules of importin $\alpha 7^{\mathrm{\triangle IBB} / \Delta \mathrm{IBB}}$ mice, the subsequent steps were characterized by abnormal nuclear condensation of elongating spermatids in importin $\alpha 7^{\Delta \mathrm{IBB} / \Delta \mathrm{IBB}}$ mice compared to WT and $\alpha 7^{-/-}$testes (Fig. 10) and mature step 15-16 sperms were absent in importin $\alpha 7^{\mathrm{ABB} / \Delta \mathrm{IBB}}$ mice. Together with the reduced number of spermatozoa and abnormal morphology of the epididymal sperms in $\alpha 7^{\mathrm{AIBB} / \Delta \mathrm{IBB}}$ mice this suggested that spermiogenesis was severely affected by importin $\alpha 7$ deficiency, which confirmed the results of gene expression analysis. We next tested whether the regulation of post-meiotic factors, that are necessary for sperm maturation, is mediated by importin $\alpha 7$. The analysis of gene expression in whole testis had already shown a slight downregulation of Tnp1, Tnp2, Prm1 and Prm2 (respective adj. p-values: 0.007, 0.06, 0.06, 0.02; Table S3) Real-time PCR analysis now demonstrated that the mRNAs of tnp1, tnp2, prm 1 and prm 2 were significantly reduced in isolated round spermatids of importin $\alpha 7^{\mathrm{\triangle IBB} / \Delta \mathrm{IBB}}$ mice

371 compared to WT (Fig. 11A). Thus, the reduced detection of protamines and transition proteins

372 in importin $\alpha 7^{\mathrm{AIBB} / \triangle \mathrm{IBB}}$ is partly due to decreased expression of these genes in round spermatids.

373 In contrast, other postmeiotic key genes were not significantly affected in importin $\alpha 7^{\Delta \mathrm{IBB} / \Delta \mathrm{IBB}}$ 
mice (Fig. 11A). Moreover, protein analysis of chromatin-bound proteins showed that Tnp2 was drastically decreased in the testes of $\alpha 7^{\mathrm{AIBB} / \Delta \mathrm{IBB}}$ mice (Fig. 11B). Yet, Tnp1 and Tnp2 immunofluorescence revealed a regular localization of these two proteins in nuclei of elongating spermatids starting at step 9 (data not shown). However, while in WT Tnp1 cannot be found in tubules later than stage I, and Tnp2 is not expressed past stage III, we constantly found Tnp1-positive sperms until stage III tubules und expression of Tnp2 was even found in sperms of stage VIII (and IX, residual sperms) tubules, suggesting a severe disturbance of protamine-histone exchange in these sperms (Fig.11C, D).

Analysis of chromatin remodeling and presence of transcription factors in importin $\alpha 7^{\Delta \mathrm{IBB} / \Delta \mathrm{IBB}}$ mice

Next we investigated the tremendous remodeling of chromatin that takes place during spermatid development, as this process is dependent on proteins that have to enter the nucleus of round and elongating spermatids. Analysis of histone H3 2- and 3-methylation as well as hyperacetylation of histone H3 (lysin 9 and lysin 14) and H4 (lysin 8 and lysin 12) did not reveal any differences of importin $\alpha 7^{\mathrm{\triangle IBB} / \Delta \mathrm{IBB}}$ and WT spermatids (data not shown). Moreover, we observed regular appearance of DNA double strand breaks as detected by $\gamma \mathrm{H} 2 \mathrm{AX}$ labelling (Fig. 7B).

392 The significant reduction in gene expression of tnp1, tnp2, prm1 and prm2 may result from impaired expression or nuclear translocation of transcription factors. In mice, the transcriptional activation of these genes is mainly regulated by the transcription factor cAMP-response element modulator (Crem) (Mali et al., 1989; Nantel et al., 1996). WT testis showed a normal expression and localization of Crem in round spermatids from stage II-VIII (Fig. S3). With the onset of elongation the Crem expression started to decline. However, no major changes in Crem expression and localization could be observed in importin $\alpha 7^{\mathrm{AIBB} / \Delta \mathrm{IBB}}$ testis (Fig. S3), suggesting that nuclear import of Crem is not affected.

400 The transcriptional regulator Brwd1 has recently been shown to be essential for spermiogenesis 401 (Pattabiraman et al., 2015). Being part of a postmeiotic transcriptional activator complex, 402 Brwd1 binds to acetylated lysine residues of histones, causing transcriptional activation. 403 Immunofluorescence of Brwd1 revealed striking differences in its expression in importin $404 \alpha 7^{\mathrm{AIBB} / \Delta \mathrm{IBB}}$ testes compared to WT testes. While in WT, positive signals could be found within 405 paraffin embedded testis sections in step 9 as well as in step 14-15 elongating spermatids, no 406 Brwd1 was found in importin $\alpha 7^{\mathrm{AIBB} / \Delta \mathrm{IBB}}$ testis. As the signals tended to be very subtle in 
paraffin sections of the testis, immunostaining was repeated in snap-frozen sections, showing very clearly the presence of Brwd1 in WT, but not in importin $\alpha 7^{\mathrm{AIBB} / \Delta \mathrm{IBB}}$ testes (Fig.12 A, B).

\section{Discussion}

411 In the present study, we analyzed the biological function of importin $\alpha 7$ (KPNA6) during

412 spermatogenesis using two different knockout mouse models, and we showed for the first time 413 that importin $\alpha 7$ is essential for mammalian male fertility. These findings are in accordance 414 with the phenotype of fruit flies lacking importin $\alpha 1$, which is the one of the three known 415 importin $\alpha$ paralogs in D. melanogaster with the highest similarity to mouse importin $\alpha 7$. The 416 importin $\alpha 1$ of $D$. melanogaster is essential for male gametogenesis exhibiting full arrest in 417 spermatogenesis and complete male infertility (Ratan et al., 2008). The sterility effect was 418 paralog-specific and resulted in defective spermatocytes with abnormal nuclear shape 419 suggesting a disturbed chromatin condensation in these cells. However, the molecular 420 mechanisms by which $D$. melanogaster importin $\alpha 1$ exerts its effects on male fertility have not 421 been assessed yet.

422 Expression of importin $\alpha 7$ in mouse testis has been investigated at the mRNA level by several techniques. It has been shown by microarray that importin $\alpha 7$ mRNA expression is increased in isolated pachytene spermatocytes and round spermatids (Holt et al., 2007; Major et al., 2011; Shima et al., 2004). Importin $\alpha 7$ mRNA is upregulated during the first spermatogenesis wave: 426 a first increase takes place from postnatal day 10 to day 20, when spermatocytes progress into 427 late pachytene stage; and a second increase occurs from postnatal day 20 to day 30 , when the 428 round spermatids become enriched (Major et al., 2011; Namekawa et al., 2006). The importin $429 \alpha 7$ protein expression pattern in germ cells during spermatogenesis detected by 430 immunohistochemistry in our current report is consistent with these data. In addition, 431 microarray data had shown that importin $\alpha 7$ mRNA is moderately expressed in in vitro cultured 432 Sertoli cells isolated from postnatal day 16 to day 18 testes (Holt et al., 2007; Shima et al., 433 2004), while in adult testis, importin $\alpha 7$ mRNA was not detected in Sertoli cells by in situ 434 hybridization (Hogarth et al., 2006). However, our present study shows, that in addition to germ 435 cells, importin $\alpha 7$ protein is also highly expressed in the nuclei of Sertoli cells throughout all 436 stages of the seminiferous epithelium in the adult testis.

437 Studies of other importin $\alpha$ isoforms in adult mouse testis have shown stage- and cell type438 specific expression of importin $\alpha 1 \alpha 3, \alpha 4$ and $\alpha 5$ (Miyamoto et al., 2012). The distinct 439 expression patterns of importin $\alpha$ proteins in testis imply that they may play defined roles during 440 mammalian spermatogenesis We confirmed the published expression of $\alpha$-importins in murine 
testis, and using specific antibodies for each importin $\alpha$ paralogue, our own comprehensive studies revealed, that importin $\alpha 7$ is the only importin $\alpha$ isoform expressed in elongating spermatids. Moreover, we detected a massive increase in importin $\alpha 7$ expression in late round and early elongating spermatids that has not been seen for any other importin $\alpha$ subtype. The infertility phenotype of importin $\alpha 7$-deficient mice underlines for the first time the hypothesis that this protein has unique functions in spermatogenesis, and other importin $\alpha$ subtypes cannot compensate for its absence.

One of the main findings of our present work is that importin $\alpha 7$ has two different functions during spermatogenesis depending on its two localizations in Sertoli cells and in developing sperms. The use of two different importin $\alpha 7$-deficient mouse lines with different expression patterns in these cell types allowed us to discriminate between these two functions as the two mouse lines display distinct phenotypes. The importin $\alpha 7^{\Delta \mathrm{IBB} / \Delta \mathrm{IBB}}$ mice are infertile and are characterized by the absence of the full-length protein in Sertoli cells as well as in developing sperms. On the other hand, importin $\alpha 7^{-/}$mice are fertile and produce sperms and this can be clearly attributed to a rescued expression of the protein in developing sperms based on a testis specific promoter in intron 1 of the kpna6 gene. The utilization of a testis-specific promoter is a well-known mechanism in male germ cells and has been shown for a variety of transcripts encoding for proteins such as angiotensin converting enzyme, c-abl, proopiomelanocortin, superoxide dismutase or $\beta$-galactosyltransferase (Hecht, 1998). In importin $\alpha 7^{-/-}$mice, germ cells, but not somatic cells of the testis produce importin $\alpha 7$ mRNA by using an alternative exon 1A, leading to mRNA with a germ cell specific 5'-untranslated region, suggesting differing transcriptional control mechanisms for importin $\alpha 7$ in germ cells and somatic cells. However, the absence of importin $\alpha 7$ in Sertoli cells seems to account for a partially reduced sperm count.

464 This finding could be confirmed by intercrossing of both lines, producing compound heterozygous offspring, which also displayed a reduced sperm count but were fertile. The reduced sperm count in these heterozygous compound mice provides clear evidence that the partial sperm count reduction can be attributed to the Sertoli cell related phenotype, as the compound heterozygous mice represent a rescue of the infertile importin $\alpha 7^{\Delta \mathrm{IBB} / \Delta \mathrm{IBB}}$ mice with expression of the full-length protein in germ cells, but not in Sertoli cells.

470 The functions of Sertoli cells include providing structural support and nutrition for developing 471 germ cells, phagocytosis of degenerating germ cells and residual bodies, establishment of the 472 BTB and release of spermatids at spermiation. In this study, we have shown that importin $\alpha 7$ is 473 highly expressed in nuclei of Sertoli cells in WT testes. Additionally, we found the number of 
Sertoli cells to be reduced in the seminiferous tubules of importin $\alpha 7^{-/-}$and $\alpha 7^{\Delta \mathrm{IBB} / \Delta \mathrm{IBB}}$ testes due to degeneration and shedding.

476 We observed a nuclear import deficiency of the AR in Sertoli cells of both mutant mouse lines. 477 It has been shown that ligand-dependent nuclear import is crucial for the function of the AR in 478 both health and disease (Becker et al., 2000; Kawate et al., 2005; Nakauchi et al., 2007; Thomas 479 et al., 2004). The unliganded AR is retained in the cytoplasm but, on binding of $5 \alpha-$ 480 dihydrotestosterone, it translocates into the nucleus and alters transcription of its target genes. 481 The nuclear import of AR has been shown to be importin $\alpha / \beta$ dependent (Cutress et al., 2008; 482 Kaku et al., 2008). Mice with Sertoli cell-specific ablation of the AR exhibit defective Sertoli cell maturation and polarization, increased permeability of the BTB and downregulation of 484 Cldn3, suggesting that Cldn3 is a transcriptional target of AR (Meng et al., 2011; Meng et al., 2005; Willems et al., 2010). We found several AR-dependent genes with the tendency towards an upregulation in importin $\alpha 7^{\mathrm{\triangle IBB} / \Delta \mathrm{IBB}}$ mice and with a normal expression in importin $\alpha 7^{-/-}$ mice. The apparent upregulation is predictable, as the loss of spermatids is much higher in $\alpha 7^{\mathrm{AIBB} / \triangle \mathrm{IBB}}$ mice than the loss of Sertoli cells, leading to a higher relative amount of Sertoli cells compared with WT testis.

Nevertheless, cldn 3 mRNA levels were significantly decreased in importin $\alpha 7^{\Delta \mathrm{IBB} / \Delta \mathrm{IBB}}$ testes while being normal in importin $\alpha 7^{-/-}$testes, suggesting that $c l d n 3$ is regulated by additional mechanisms that differ between the two mutant lines; moreover, Chihara et al. found cldn 3 not only to be expressed by Sertoli cells, but mainly by Stra8 positive germ cells (Chihara et al., 2013), which could explain the differences found in importin $\alpha 7^{\triangle \mathrm{IBB} / \Delta \mathrm{IBB}}$ and $\alpha 7^{-/-}$testes. The reduced expression of cldn 3 mRNA, however, does not affect the correct localization of the protein in stage VIII seminiferous tubuli in importin $\alpha 7^{\mathrm{AIBB} / \Delta \mathrm{IBB}}$ mice, although the quantitative amount of a protein is difficult to estimate by immunohistochemistry. It has been shown that during stages VII and VIII the BTB is dynamically remodeled as preleptotene spermatocytes pass through the barrier (Bremner et al., 1994; Dym and Fawcett, 1970). We observed a relative reduction in leptotene/zygotene spermatocytes of about $25 \%$ in importin $\alpha 7^{\mathrm{AIBB} / \Delta \mathrm{IBB}}$ and $\alpha 7^{-/-}$ seminiferous tubules which would be consistent with a meiotic delay due to a prolonged leptotene/zygotene phase as it had been observed in cldn3 knockdown mice (Chihara et al.). The presence of testis-specific autoantibodies in the blood of both mutant lines also suggests a disturbance of the BTB integrity which depends on Sertoli cells. However, we could not detect higher IgG levels in testes of both mouse lines compared to WT and in vitro biotin diffusion assays did also not confirm a permanently disturbed BTB. The contradictory results regarding BTB stability lead us to speculate that there is a partially compromised BTB, resulting in 
presence of autoantibodies and delayed passage of leptotene/zygotene spermatocytes. Although both mutant mouse lines exhibit a loss of leptotene/zygotene spermatocytes, only importin $\alpha 7^{\mathrm{AIBB} / \Delta \mathrm{IBB}}$ mice show an even more pronounced loss of pachytene spermatocytes and round spermatids, suggesting that the latter can be attributed to the defective importin $\alpha 7$ in germ cells. Although we detected defective sperm orientation in both mutant lines, which can be attributed to defective Sertoli cell function, the sperm transport through the epithelium was found to be dysregulated only in importin $\alpha 7^{\mathrm{\Delta IBB} / \Delta \mathrm{IBB}}$ mice but normal in importin $\alpha 7^{-/-}$mice. The fact, that in $\alpha 7^{\mathrm{AIBB} / \Delta \mathrm{IBB}}$ testes stage IX-XII tubules frequently contain spermatids at different maturation steps leads to the conclusion that spermatids are not properly released from the seminiferous epithelium. We were not able to detect such residual spermatids in importin $\alpha 7^{-/-}$testis, suggesting that a failure in coordinated spermiogenesis rather than in Sertoli cell-dependent release accounts for the residual spermatids.

A striking finding of our present study was, that the Sertoli cells of both mutant lines display abnormal organization of the intermediate filament vimentin. While vimentin is stretched across the Sertoli cell cytosol in WT testis, both mutant mouse lines showed a concentration around the Sertoli cell nucleus with no extensions. Similar findings have been found in mice with a defective cytoplasmic dynein 1 heavy chain and in mice that have been depleted of raptor, a key component of mTORC1 (Wen et al., 2018; Xiong et al., 2018). However, in both of these mouse lines, the phenotype included a severely disorganization of actin and microtubules. We could not find a disordered localization of Sertoli cell microtubuli in importin $\alpha 7^{\Delta \mathrm{IBB} / \Delta \mathrm{IBB}}$ or importin $\alpha 7^{-/-}$mice, excluding major morphological changes of Sertoli cell cytoplasm which still stretched out into the tubular lumen.

By H\&E staining of 6 weeks old testes we found retardation in the first wave of spermatogenesis which was confirmed by detailed analyses in 14 and 21 days old testes. While early pachytene spermatocytes could be detected in day 14 WT testes, they were absent in importin $\alpha 7^{\triangle \mathrm{IBB} / \Delta \mathrm{IBB}}$ mice. Moreover, at day 21, many tubules containing leptotene/zygotene spermatocytes were found in importin $\alpha 7^{\mathrm{AIBB} / \triangle \mathrm{IBB}}$ mice, while in WT testes most of the spermatocytes had already reached pachytene stage. The reason for this delay is not completely clear but it fits to previous reports of importin $\alpha 7$ being upregulated starting at postnatal day 10, suggesting a very specific role at this time point (Major et al., 2011; Namekawa et al., 2006).

538 Multiple molecular events have to occur for a round spermatid to become a mature sperm. These events include chromatin condensation, reorganization of the spermatid nucleus, formation of an acrosome and assembly of a sperm tail (Sassone-Corsi, 2002). It has been shown that a number of postmeiotic proteins including transition nuclear proteins 1 and 2 (Tnp1 and Tnp2), 
protamines 1 and 2 (Prm1 and Prm2), meiosis expressed gene 1 protein (Meig1), outer dense fiber protein 1 (Odf1), lysine-specific demethylase 3a ( $\mathrm{Jhdm} 2 \mathrm{a})$, activator of Crem in testis

544 (Act), and F-actin-capping protein subunit alpha-3 (Capza3), are important for spermiogenesis

545 (Geyer et al., 2009; Kotaja et al., 2004; Liu et al., 2010; Okada et al., 2007; Salzberg et al., 546 2010; Yang et al., 2012; Zhang et al., 2009). The transition from round spermatids to mature 547 spermatozoa was severely affected in $\alpha 7^{\triangle \mathrm{IBB} / \Delta \mathrm{IBB}}$ mice, since the few spermatozoa that did form 548 in $\alpha 7^{\mathrm{\triangle IBB} / \triangle \mathrm{IBB}}$ animals (3\% of WT levels) displayed abnormal heads. Spermiogenesis requires extensive chromatin condensation. Histone displacement, a process in which histones are initially replaced by Tnp1 and Tnp2 and subsequently by Prm1 and Prm 2, is required for chromatin condensation. Accordingly, the genetic ablation of transition proteins or protamines causes defective spermiogenesis (Cho et al., 2001; Yu et al., 2000; Zhao et al., 2004; Zhao et al., 2001) comparable to the phenotype of importin $\alpha 7^{\Delta \mathrm{IBB} / \Delta \mathrm{IBB}}$ males. By RNAseq we found that importin $\alpha 7$ deficiency reduced tnp 1, tnp 2, prm1, and prm 2 mRNA expression in the testis and this effect was even more pronounced when isolated round spermatids were analyzed by quantitative real-time PCR. Moreover, total chromatin-bound Tnp2 was markedly reduced in testes of importin $\alpha 7^{\triangle \mathrm{IBB} / \Delta \mathrm{IBB}}$ mice as assessed by western blot. Additionally, a prolonged localization of Tnp1 and Tnp2 was detected in spermatids of importin $\alpha 7^{\Delta \mathrm{IBB} / \Delta \mathrm{IBB}}$ mice, confirming the defective histone/protamine exchange.

560 The transcriptional activation of Tnp and Prm genes is mainly regulated by the transcription 561 factor Crem and transcriptional activity of Crem is regulated by Act (Fimia et al., 1999; Mali 562 et al., 1989; Nantel et al., 1996). It has been demonstrated that the Crem-regulated gene expression pathway is essential for normal spermatogenesis (Deng and Lin, 2002; Giorgini et al., 2002; Kotaja et al., 2004; Nantel et al., 1996). Like importin $\alpha 7$, Crem and Act are also highly expressed in round spermatids (De Cesare et al., 2003; Delmas et al., 1993). Analysis of

566 Crem expression by immunofluorescence, however, did not reveal a significant reduction or 567 mislocalization in importin $\alpha 7^{\mathrm{\triangle IBB} / \triangle \mathrm{IBB}}$ testis. Moreover, other above mentioned postmeiotic 568 (Crem-regulated) genes did not show a significantly reduced expression in importin $\alpha 7^{\mathrm{AIBB} / \triangle \mathrm{IBB}}$ 569 testes.

570 The transcriptional regulator Brwd1 has recently been shown to be essential for spermiogenesis 571 (Pattabiraman et al., 2015). Although a distinct pathway has not been found yet, the altered 572 transcription of postmeiotic genes in Brwd1-defective testes has been suggested to cause male 573 infertility. We found a striking reduction of Brwd1 testicular signals in importin $\alpha 7^{\Delta \mathrm{IBB} / \triangle \mathrm{IBB}}$ 574 testes that could be causative for the infertility in this mouse line. 
A gene set enrichment analysis of the RNAseq data clearly indicated a downregulation of cilium- and sperm motility related processes in importin $\alpha 7^{\Delta \mathrm{IBB} / \Delta \mathrm{IBB}}$ mice, corroborating the finding of defective spermatogenesis. Upregulated pathways include lysosomal and early endosome GO terms, which might be a consequence of the decreased importin $\alpha 7$ function. An upstream analysis of putative transcription factors singled out a downregulation of $\mathrm{Rfx} 2$ (Regulatory Factor X2) gene targets. While the transcription factor itself was not differentially regulated relative to WT, its targets related to cilium, axoneme, microtubule and sperm motility were, which was evident from a comparison of our RNAseq data to a testis transcriptome of Rfx2 knockout mice (Wu et al., 2016). Thus, it might be possible that the translocation of $\mathrm{Rf} 2$ into the nucleus could be affected in importin $\alpha 7^{\mathrm{AIBB} / \Delta \mathrm{IBB}}$ testes.

The well-known function of importin $\alpha 7$ as part of the nuclear import system raises the possibility that import deficiency of one or more factors contribute to the phenotype directing the attention towards chromatin modifying proteins and transcriptional regulators. Having investigated transcriptional regulators as CREM and Brwd1 during the course of this study, there are many more possible factors that could be potentially involved in the phenotype of importin $\alpha 7$-deficient mice. The TBP-related factor Trf2, which is abundantly expressed in testis, is essential for mouse spermiogenesis, just as well as Taf7l, that has been shown to cooperate with Trf2 to regulate expression of postmeiotic genes (Zhang et al., 2001; Zhou et al., 2013). In eukaryotic cells, the transcription of genes is carried out by RNA polymerase II. Depending on its need for transcription, the RNA polymerase II shuttles between nucleus and cytoplasm and this shuttling has been suggested to represent a mechanism of transcriptional control in particular in spermatogenesis (Custodio et al., 2006).

A large number of studies have identified spermiogenesis-relevant genes that function in posttranscriptional control in concert with importin $\alpha$. In the developing male gamete RNA synthesis terminates during mid-spermiogenesis, which is long before the spermatid completes

600 its differentiation into the spermatozoon, making a coordinated translational regulation of 601 stored mRNAs essential, and the formation of respective RNA-protein complexes has 602 previously been shown to be regulated by importin $\alpha$ (Hecht, 1998; Sato and Maquat, 2009).

603 The importance of such RNA-regulating proteins for a well-ordered germ cell development is 604 underlined by an arrest at early spermiogenesis in mice lacking Piwi which regulates germ cell 605 expressed miRNAs and piRNAs involved in mRNA silencing (Deng and Lin, 2002; Grivna et 606 al., 2006). A further example is MSY2, a DNA/RNA binding protein solely expressed in germ 607 cells, which has been implicated in stabilization of transcripts and translational repression. 
MSY2-deficient mice show a spermatogenic arrest in late round spermatids and infertility like importin $\alpha 7^{\mathrm{\Delta IBB} / \Delta \mathrm{IBB}}$ mice (Yang et al., 2007).

610 The cap binding proteins CBP20 and CBP80 bind in the nucleus to newly formed transcripts 611 and regulate their splicing, 3'-end formation, and nuclear export as well as the pioneer round 612 of translation. The binding of CBP20 and CBP80 to mRNA, in turn, is tightly regulated by 613 importin $\alpha$ and $\beta$ providing a further mechanism how importins could be involved in 614 posttranscriptional control in spermatogenesis (Dias et al., 2009). It will be interesting to 615 execute detailed analyses of these mechanisms in importin $\alpha 7$-deficient mice.

616 Taken together, in the present study we have shown for the first time that importin $\alpha 7$ is essential 617 for mammalian male fertility. Importin $\alpha 7$-deficient testes exhibit a disturbed spermatogenesis 618 with incomplete transition from preleptotene to leptotene spermatocytes and defective 619 progression of round spermatids to mature spermatozoa. Using two different importin $\alpha 7$ 620 deficient mouse lines for our analyses, we could clearly relate the above described phenomena to the missing expression of importin $\alpha 7$ in Sertoli cells and elongating spermatids, respectively.

622 The compromised function of Sertoli cells is correlated with a partial decrease of germ cells and results in reduced sperm count. In contrast, impaired expression of importin $\alpha 7$ in round and elongating spermatids leads to complete arrest of spermiogenesis resulting in severe oligozoospermia. Since at the level of round spermatids importin $\alpha 7$ is the main expressed $\alpha-$ importin, its deficiency has rather pleiotropic effects, including transcriptional processes, proper localization of proteins and development of the sperm flagellum and shows its biggest impact during spermiogenesis when spermatids start to elongate. Although we revealed severe impairments in expression and localization of transition nuclear proteins and protamines, as well as of the transcription factor Brwd1, and altered expression of Rfx 2 target genes, further investigations have to be performed to identify all the cellular and molecular mechanisms involved in the complex phenotype of infertility observed in $\alpha 7^{\mathrm{AIBB} / \Delta \mathrm{IBB}}$ mice.

\section{Materials and Methods}

Animals - Importin $\alpha 7^{-/-}$and $\alpha 7^{\mathrm{AIBB} / \Delta \mathrm{IBB}}$ mice were generated as described previously (Rother et al., 2011). Animals were backcrossed for 10 generations to C57B16/N background. If not stated otherwise, male mice aged 10-20 weeks were used for the analyses. All experiments were performed according to national and institutional guidelines and were approved by the relevant authority [Landesamt für Gesundheit und Soziales (LaGeSo), Berlin, Germany].

640 Western blot - Mouse testes were collected and homogenized in RIPA-Buffer supplemented 641 with protease inhibitor cocktail (Sigma-Aldrich, St. Louis, USA). Following sonication and 
642 centrifugation, protein concentrations in the tissue extracts were measured by using 643 Bicinchorinic Acid Solution / Coppersulfate Solution 50:1 (Sigma-Aldrich, St. Louis, USA). $64440 \mu \mathrm{g}$ of total protein was separated by SDS-PAGE. After the transfer of proteins, the PVDF 645 membrane was blocked by Odyssey blocking solution (LiCor, Bad Homburg, Germany) and 646 subsequently incubated with primary antibodies at $4{ }^{\circ} \mathrm{C}$ overnight. On the next day, the 647 membrane was incubated with an IRDye- coupled secondary antibody for $1 \mathrm{~h}$ at room 648 temperature and detection was performed using the Odyssey Infrared Scanner (LiCor, Bad 649 Homburg, Germany). Signals were quantified using the Odyssey Infrared Scanner software 650 (LiCor, Bad Homburg, Germany). The generation of C-terminal and N-terminal antibodies 651 against importin $\alpha 7$ was accomplished using standard protocols and has been described 652 previously (Kohler et al., 1999). The complete list of antibodies and conditions is found in 653 supplemental data (Table S1).

$654 \boldsymbol{R}$ A A-isolation, reverse transcription and PCR - Murine liver and testis were homogenized in 655 trizol (FIRMA) and extracted with chloroform, subsequently precipitated in isopropanol and 656 washed with 70\% ethanol. The pellet was dried and resuspended in DEPC water. Then RNA 657 was digested with DNAse I, and $2 \mu \mathrm{g}$ of digested RNA was subjected to reverse transcription 658 using a standard protocol. PCR was performed using $10 \mathrm{ng}$ of cDNA, the used primers are listed 659 in supplemental data (Table S2).

660 Testosterone measurement - Blood samples were collected from 10-weeks-old mice by cardiac 661 puncture. Serum samples were prepared as described earlier (Jeyaraj et al., 2005). The concentrations of testosterone in the serum samples were measured by using a Testosterone EIA kit (Cayman Chemical Company, Michigan, USA).

664 Histological analysis - Testis and Epididymis were fixed in neutral buffered 4\% formalin. After fixation, tissues were dehydrated in increasing concentrations of ethanol, embedded in paraffin wax, and sectioned at a thickness of $5 \mu \mathrm{m}$. Sections were deparaffinised, rehydrated and stained with hematoxylin and eosin according to standard protocols. For quantification of diameters of seminiferous tubules, images of H\&E stained testis sections ( 5 animals per group) were taken using Keyence microscope (Keyence, Bioreva BZ-9000, Germany) and analyzed; 30 tubules per animal were measured using ImageJ software.

671 Epididymal sperm count - Sperm count was performed as described previously (Liu et al., 672 2010; Wu et al., 2000). Briefly, one caudal epididymis was used for histological examination, 673 and the other was minced in $1 \mathrm{ml}$ of PBS. Sperms were allowed to disperse into solution by incubating for $5 \mathrm{~min}$ at room temperature. An aliquot of the sperm/saline mixture was then counted in a hemocytometer. The hemocytometer count was multiplied by appropriate volume 
676 and dilution factors to give a total cauda epididymal sperm count. The average number of sperms per epididymis was calculated from 4-8 mice for each genotype group.

Immunohistochemical analysis -For IF staining sections underwent deparaffination followed by rehydration and antigen retrieval using either citrate buffer pH6 or Tris-EDTA buffer pH9 for 20 minutes, wherever appropriate. The sections were then treated with $10 \%$ normal donkey serum for $1 \mathrm{~h}$ at room temperature and subsequently incubated with primary antibody overnight at $4^{\circ} \mathrm{C}$. On the next day, sections were washed with PBS, incubated with secondary antibody for $2 \mathrm{~h}$ at room temperature, washed again with PBS and incubated for $1 \mathrm{~h}$ at room temperature with peanut agglutinin, subsequently washed again and embedded in mounting medium containing DAPI (Vectashield, Vector Laboratories/Biozol, Germany). Whenever needed, the immunostaining was performed on $10 \mu \mathrm{m}$ thick frozen sections of testis fixed in neutral buffered $4 \%$ formalin. The complete list of antibodies and conditions is found in supplemental data (Table S1). Images of stained tissue sections were taken using a fluorescence microscope (Keyence, Bioreva BZ-9000, Germany) or a confocal fluorescence microscope (Leica TCS SPE). For cell counts, at least 100 seminiferous tubuli of 3 mice per group were analyzed using ImageJ software.

Quantitative realtime PCR - Total RNA was extracted from WT, importin $\alpha 7^{-/-}$and importin $693 \alpha 7^{\triangle \mathrm{IBB} / \Delta \mathrm{IBB}}$ testes and FACS sorted germ cells using RNeasy Mini Kits (Qiagen, Hilden, 694 Germany). First-strand DNA synthesis was performed using M-MLV Reverse Transcriptase (Invitrogen, Darmstadt, Germany) and random primers according to the manufacturer's instructions. Quantitative PCR was performed using Go Taq (Promega, Mannheim, Germany) on an IQ 5 Multicolour Realtime PCR Detection System (Bio-Rad laboratories, München, Germany). Relative gene expression was calculated using the $\Delta \Delta \mathrm{Ct}$ method with GAPDH as normalizing gene. Primer sequences are listed in supplemented data (Table S2).

Autoantibody detection - Autoantibodies against sperm proteins were detected as described previously (Meng et al., 2011). Briefly, blots with testicular proteins of two months old WT mice were incubated with a 1:50 dilution of either WT, importin $\alpha 7^{\Delta \mathrm{IBB} / \Delta \mathrm{IBB}}$ or $\alpha 7^{-/-}$mutant sera overnight at $4^{\circ} \mathrm{C}$. Primary antibodies were detected with an IRDye coupled secondary antimouse antibody for $1 \mathrm{~h}$ at room temperature and detection was performed using the Odyssey Infrared Scanner (LiCor, Bad Homburg, Germany).

Biotin-labelling of blood-testis barrier - Mice were sacrificed by cervical dislocation and testis were carefully pulled out of the body without extracting them. $50 \mu 1$ of $1 \mathrm{mM} \mathrm{CaCl}_{2}$ containing $10 \mathrm{mg} / \mathrm{ml}$ biotin (EZ-Link Sulfo-NHS-LC-Biotin, Pierce, Dallas, USA) were injected with a $0.4 \mathrm{~mm}$ needle into one testis. As a control, the second testis was injected with $50 \mu 1$ of $1 \mathrm{mM}$ 
$\mathrm{CaCl}_{2}$ only. After 30 min of distribution of the injected solution via diffusion the testes were dissected and snap frozen in Tissue-Tek OCT compound (Sakura Finetek, Netherlands). $15 \mu \mathrm{m}$ cryoslices were cut, mounted on glass slides and fixed with 4\% PFA for $15 \mathrm{~min}$. After washing, the sections were incubated with streptavidin-Cy5 directly, coversliped and observed under a fluorescence microscope (Keyence, Bioreva BZ-9000).

BrdU injection - To analyze proliferation of germ cells, animals received two intraperitoneal injections of bromodeoxyuridine (BrdU; $50 \mathrm{mg} / \mathrm{kg}$ body weight dissolved in $0.9 \% \mathrm{NaCl}$; Sigma-Aldrich) $2 \mathrm{~h}$ apart and were sacrificed $2 \mathrm{~h}$ after the second injection.

\section{RNAsequencing}

A total amount of $1 \mu \mathrm{g}$ RNA per sample was used as input material for the RNA sample preparations. Sequencing libraries were generated using NEBNext ${ }^{\circledR}$ UltraTM RNA Library Prep Kit for Illumina ${ }^{\circledR}$ (NEB, USA) following manufacturer's recommendations and index codes were added to attribute sequences to each sample. Briefly, mRNA was purified from total RNA using poly-T oligo-attached magnetic beads. Fragmentation was carried out using divalent cations under elevated temperature in NEBNext First Strand Synthesis Reaction Buffer (5X). First strand cDNA was synthesized using random hexamer primer and M-MuLV Reverse Transcriptase (RNase H-). Second strand cDNA synthesis was subsequently performed using DNA Polymerase I and RNase H. Remaining overhangs were converted into blunt ends via exonuclease/polymerase activities. After adenylation of 3' ends of DNA fragments, NEBNext Adaptor with hairpin loop structure were ligated to prepare for hybridization. In order to select cDNA fragments of preferentially $150 \sim 200 \mathrm{bp}$ in length, the library fragments were purified with AMPure XP system (Beckman Coulter, Beverly, USA). Then $3 \mu 1$ USER Enzyme (NEB, USA) was used with size-selected, adaptor- ligated cDNA at $37{ }^{\circ} \mathrm{C}$ for $15 \mathrm{~min}$ followed by 5 min at $95{ }^{\circ} \mathrm{C}$ before PCR. PCR was performed with Phusion High-Fidelity DNA polymerase, Universal PCR primers and Index (X) Primer. At last, PCR products were purified (AMPure XP system) and library quality was assessed on the Agilent Bioanalyzer 2100 system. Fastq reads were pseudo-aligned to the mm10 genome assembly using kallisto (version 0.46) and transcript read counts were aggregated to Ensembl Gene IDs for further analysis. Differential gene expression analysis was performed via the R library sleuth (Pimentel et al., 2017). Significance and effect sizes of differential gene regulation were calculated from the likelihood ratio and the Wald test, respectively, as implemented in the sleuth package. GO term and

741 pathway enrichment analyses were performed based on the effect size between the WT and

742 knockdown strains using the generally applicable Gen Set Enrichment Analysis (GSEA), 743 GAGE, which determines whether a set of genes is systematically up- or downregulated as a 
whole (Luo et al., 2009). For gene set definitions, we used the Molecular Signatures Database (MSigDB) from the R msigdf package (Version 7.1) (Liberzon et al., 2015). Gene sets with less than 3 or those with more than 500 members were discarded for statistical robustness and biological interpretation. Putative transcription factor activity from RNA-seq data was assessed per pseudo timepoint against healthy controls using the mouse gene set resource DoRothEA v1, which provides a curated collection of transcription factor and target genes interactions (the regulon) from different sources (Garcia-Alonso et al., 2019). Only interactions with high, likely, and medium confidence (levels A, B, C) were considered. Regulons were statistically evaluated using the R package viper (v1.22.0; row-wise t-tests) (Alvarez et al., 2016). Only regulons having at least 15 expressed gene targets were considered.

Testicular single-cell suspensions - Cells were isolated from 3-months-old WT and $\alpha 7^{\mathrm{ABB} / \Delta \mathrm{IBB}}$ male mice according to a protocol of Getun et al. with slight modifications (Getun et al., 2011). Briefly, tunica albuginea was removed, and the seminiferous tubules were fragmented with scissors. The fragments were dissociated in dispase (BD Biosciences) with $10 \mathrm{U} / \mathrm{ml}$ DNAse I for $40 \mathrm{~min}$ at $37^{\circ} \mathrm{C}$. After centrifugation, the pelleted tubules were resuspended in trypLE express enzyme (Life Technologies) with $10 \mathrm{U} / \mathrm{ml}$ DNAse I and incubated at $32^{\circ} \mathrm{C}$ for $20 \mathrm{~min}$. The resulting whole cell suspension was successively washed with Gey's balanced salt solution (GBSS, Sigma-Aldrich). Then the cell pellet was resuspended in GBSS supplemented with 10\% fetal calf serum and $10 \mathrm{U} / \mathrm{ml}$ DNAse I. The dissociated testis sample was then passed through a $40 \mu \mathrm{m}$ GBSS pre-wetted disposable cell strainer. Final staining was performed by adding Hoechst $33342(5 \mu \mathrm{g} / \mathrm{ml})$ to the dissociated testis sample and incubating at $32^{\circ} \mathrm{C}$ for $1 \mathrm{~h}$. Before analysis, propidium iodide (PI at $2 \mu \mathrm{g} / \mathrm{ml}$ ) was added to exclude dead cells.

FACS sorting - FACS sorting was performed according to a slightly modified protocol of Bastos et al. (Bastos et al., 2005). Briefly, the enrichment of pachytene spermatocytes and round spermatids was performed on a FACSAria III cell sorter from BD Biosciences. Live stained testicular cells were excited with a near UV laser $(375 \mathrm{~nm})$, the two parameters Hoechst blue (450/40 BP) and Hoechst red (670 LP) were used to identify and sort.

Extraction of chromatin-bound proteins - Extraction of basic nuclear proteins from mouse testis was performed according to Eckhardt (Eckhardt and Wang-Eckhardt, 2015). Briefly, one testis was homogenized in ice-cold NETN buffer, centrifuged at 12,000 x g for $10 \mathrm{~min}$, resuspended in NETN buffer and centrifuged again. Then, the pellet was resuspended in $0.2 \mathrm{~N}$ $\mathrm{HCl}$ and incubated overnight at $4^{\circ} \mathrm{C}$. After centrifugation at $12,000 \times \mathrm{g}$ for $10 \mathrm{~min}$, the supernatant containing basic nuclear proteins was neutralized with $1 \mathrm{M}$ Tris- $\mathrm{HCl}(\mathrm{pH} 8.5)$ and protein concentration was determined. 
778 Statistics - Statistical analysis was performed with Prism7 (GraphPad). Results are presented as means \pm SEM. Significance was determined by using ANOVA (where 3 groups were compared) or the unpaired two-tailed Student's t test. For distribution of the genotype after heterozygous mating the binominal test was used. Significance was assumed for $\mathrm{p}<0.05\left(^{*}, \mathrm{p}\right.$ $<0.05 ; * *, \mathrm{p}<0.01 ; * * *, \mathrm{p}<0.001 ; * * * *, \mathrm{p}<0.0001 ;$ n.s., not significant).

\section{Acknowledgements}

785

The authors wish to thank Anne Hahmann, Andrea Rodak and Madeleine Skorna-Nussbeck for technical assistance. We thank Laura Pelz and Fritz Rathjen for providing a BT-IgSF knockout mouse for control of BTB experiments. We also thank Hans-Peter Rahn for his help with the FACS sorting of cells and the Advanced Light Microscopy technology platform of the MDC for their technical support.

\section{Data Access}

792 The RNAseq data is available through Gene Expression Omnibus (GEO) under the ID GSE160969.

793 Reviewers can access the data at https://www.ncbi.nlm.nih.gov/geo/query/acc.cgi?acc=GSE160969

794 using the token 'qxofaykwndszjix'.

\section{Competing interests}

797 We declare that we have no significant competing financial, professional, or personal interests that might have influenced the performance or presentation of the work described in this manuscript.

800

Funding

The work leading to this manuscript was partly supported by the DFG (BA 1374/21-1 and RO 4779/1-2).

\section{References}

Alvarez, M.J., Y. Shen, F.M. Giorgi, A. Lachmann, B.B. Ding, B.H. Ye, and A. Califano. 2016. Functional characterization of somatic mutations in cancer using network-based inference of protein activity. Nature genetics. 48:838-847.

Bastos, H., B. Lassalle, A. Chicheportiche, L. Riou, J. Testart, I. Allemand, and P. Fouchet. 2005. Flow cytometric characterization of viable meiotic and postmeiotic cells by Hoechst 33342 in mouse spermatogenesis. Cytometry A. 65:40-49.

Becker, M., E. Martin, J. Schneikert, H.F. Krug, and A.C. Cato. 2000. Cytoplasmic localization and the choice of ligand determine aggregate formation by androgen receptor with amplified polyglutamine stretch. $J$ Cell Biol. 149:255-262. 
Bellve, A.R., and W. Zheng. 1989. Growth factors as autocrine and paracrine modulators of male gonadal functions. $J$ Reprod Fertil. 85:771-793.

Blanco-Rodriguez, J. 2009. $\gamma \mathrm{H} 2 \mathrm{AX}$ marks the main events of the spermatogenic process. Microscopy research and technique. 72:823-832.

Bremner, W.J., M.R. Millar, R.M. Sharpe, and P.T. Saunders. 1994. Immunohistochemical localization of androgen receptors in the rat testis: evidence for stage-dependent expression and regulation by androgens. Endocrinology. 135:1227-1234.

Celeste, A., S. Petersen, P.J. Romanienko, O. Fernandez-Capetillo, H.T. Chen, O.A. Sedelnikova, B. Reina-San-Martin, V. Coppola, E. Meffre, M.J. Difilippantonio, C. Redon, D.R. Pilch, A. Olaru, M. Eckhaus, R.D. Camerini-Otero, L. Tessarollo, F. Livak, K. Manova, W.M. Bonner, M.C. Nussenzweig, and A. Nussenzweig. 2002. Genomic instability in mice lacking histone H2AX. Science. 296:922-927.

Chihara, M., R. Ikebuchi, S. Otsuka, O. Ichii, Y. Hashimoto, A. Suzuki, Y. Saga, and Y. Kon. 2013. Mice stage-specific claudin 3 expression regulates progression of meiosis in early stage spermatocytes. Biol Reprod. 89:3.

Cho, C. 2005. Mammalian ADAMs with Testis-Specific or -Predominant Expression. In The ADAM Family of Proteases. N.M. Hooper and U. Lendeckel, editors. Springer US, Boston, MA. 239259.

Cho, C., W.D. Willis, E.H. Goulding, H. Jung-Ha, Y.C. Choi, N.B. Hecht, and E.M. Eddy. 2001. Haploinsufficiency of protamine-1 or -2 causes infertility in mice. Nature genetics. 28:82-86.

Clermont, Y. 1993. Introduction to the Sertoli cell. The sertoli cell. Clearwater, FL: Cache River.

Custodio, N., M. Antoniou, and M. Carmo-Fonseca. 2006. Abundance of the largest subunit of RNA polymerase II in the nucleus is regulated by nucleo-cytoplasmic shuttling. Exp Cell Res. 312:2557-2567.

Cutress, M.L., H.C. Whitaker, I.G. Mills, M. Stewart, and D.E. Neal. 2008. Structural basis for the nuclear import of the human androgen receptor. J Cell Sci. 121:957-968.

De Cesare, D., G.M. Fimia, S. Brancorsini, M. Parvinen, and P. Sassone-Corsi. 2003. Transcriptional control in male germ cells: general factor TFIIA participates in CREM-dependent gene activation. Molecular endocrinology. 17:2554-2565.

Delmas, V., F. van der Hoorn, B. Mellstrom, B. Jegou, and P. Sassone-Corsi. 1993. Induction of CREM activator proteins in spermatids: down-stream targets and implications for haploid germ cell differentiation. Molecular endocrinology. 7:1502-1514.

Deng, W., and H. Lin. 2002. miwi, a murine homolog of piwi, encodes a cytoplasmic protein essential for spermatogenesis. Developmental cell. 2:819-830.

Dias, S.M., K.F. Wilson, K.S. Rojas, A.L. Ambrosio, and R.A. Cerione. 2009. The molecular basis for the regulation of the cap-binding complex by the importins. Nat Struct Mol Biol. 16:930-937.

Dym, M., and D.W. Fawcett. 1970. The blood-testis barrier in the rat and the physiological compartmentation of the seminiferous epithelium. Biol Reprod. 3:308-326.

Eckhardt, M., and L. Wang-Eckhardt. 2015. A commercial human protamine-2 antibody used in several studies to detect mouse protamine-2 recognizes mouse transition protein-2 but not protamine-2. Mol Hum Reprod. 21:825-831.

Eddy, E.M., and D.A. O'Brien. 1998. Gene expression during mammalian meiosis. Curr Top Dev Biol. 37:141-200.

Fimia, G.M., D. De Cesare, and P. Sassone-Corsi. 1999. CBP-independent activation of CREM and CREB by the LIM-only protein ACT. Nature. 398:165-169.

Garcia-Alonso, L., C.H. Holland, M.M. Ibrahim, D. Turei, and J. Saez-Rodriguez. 2019. Benchmark and integration of resources for the estimation of human transcription factor activities. Genome Res. 29:1363-1375.

Getun, I.V., B. Torres, and P.R. Bois. 2011. Flow cytometry purification of mouse meiotic cells. J Vis Exp.

Geyer, C.B., A.L. Inselman, J.A. Sunman, S. Bornstein, M.A. Handel, and E.M. Eddy. 2009. A missense mutation in the Capza3 gene and disruption of F-actin organization in spermatids of repro32 infertile male mice. Developmental biology. 330:142-152.

Giorgini, F., H.G. Davies, and R.E. Braun. 2002. Translational repression by MSY4 inhibits spermatid differentiation in mice. Development. 129:3669-3679. 
Grivna, S.T., B. Pyhtila, and H. Lin. 2006. MIWI associates with translational machinery and PIWIinteracting RNAs (piRNAs) in regulating spermatogenesis. Proc Natl Acad Sci U S A. 103:13415-13420.

Hamer, G., H.L. Roepers-Gajadien, A. van Duyn-Goedhart, I.S. Gademan, H.B. Kal, P.P. van Buul, and D.G. de Rooij. 2003. DNA double-strand breaks and gamma-H2AX signaling in the testis. Biol Reprod. 68:628-634.

Hecht, N.B. 1998. Molecular mechanisms of male germ cell differentiation. Bioessays. 20:555-561.

Hermo, L., R.M. Pelletier, D.G. Cyr, and C.E. Smith. 2010. Surfing the wave, cycle, life history, and genes/proteins expressed by testicular germ cells. Part 1: background to spermatogenesis, spermatogonia, and spermatocytes. Microscopy research and technique. 73:241-278.

Hogarth, C.A., S. Calanni, D.A. Jans, and K.L. Loveland. 2006. Importin alpha mRNAs have distinct expression profiles during spermatogenesis. Developmental dynamics : an official publication of the American Association of Anatomists. 235:253-262.

Holt, J.E., J.D. Ly-Huynh, A. Efthymiadis, G.R. Hime, K.L. Loveland, and D.A. Jans. 2007. Regulation of Nuclear Import During Differentiation; The IMP alpha Gene Family and Spermatogenesis. Current genomics. 8:323-334.

Jeyaraj, D.A., G. Grossman, and P. Petrusz. 2005. Altered bioavailability of testosterone in androgenbinding protein-transgenic mice. Steroids. 70:704-714.

Johnson, L., D.L. Thompson, Jr., and D.D. Varner. 2008. Role of Sertoli cell number and function on regulation of spermatogenesis. Anim Reprod Sci. 105:23-51.

Kaku, N., K. Matsuda, A. Tsujimura, and M. Kawata. 2008. Characterization of nuclear import of the domain-specific androgen receptor in association with the importin alpha/beta and Ranguanosine 5'-triphosphate systems. Endocrinology. 149:3960-3969.

Kawate, H., Y. Wu, K. Ohnaka, R.H. Tao, K. Nakamura, T. Okabe, T. Yanase, H. Nawata, and R. Takayanagi. 2005. Impaired nuclear translocation, nuclear matrix targeting, and intranuclear mobility of mutant androgen receptors carrying amino acid substitutions in the deoxyribonucleic acid-binding domain derived from androgen insensitivity syndrome patients. The Journal of clinical endocrinology and metabolism. 90:6162-6169.

Kohler, M., S. Ansieau, S. Prehn, A. Leutz, H. Haller, and E. Hartmann. 1997. Cloning of two novel human importin-alpha subunits and analysis of the expression pattern of the importin-alpha protein family. FEBS Lett. 417:104-108.

Kohler, M., C. Speck, M. Christiansen, F.R. Bischoff, S. Prehn, H. Haller, D. Gorlich, and E. Hartmann. 1999. Evidence for distinct substrate specificities of importin alpha family members in nuclear protein import. Mol Cell Biol. 19:7782-7791.

Kotaja, N., D. De Cesare, B. Macho, L. Monaco, S. Brancorsini, E. Goossens, H. Tournaye, A. Gansmuller, and P. Sassone-Corsi. 2004. Abnormal sperm in mice with targeted deletion of the act (activator of cAMP-responsive element modulator in testis) gene. Proc Natl Acad Sci US A. 101:10620-10625.

Liberzon, A., C. Birger, H. Thorvaldsdóttir, M. Ghandi, J.P. Mesirov, and P. Tamayo. 2015. The Molecular Signatures Database (MSigDB) hallmark gene set collection. Cell Syst. 1:417-425.

Liu, Z., S. Zhou, L. Liao, X. Chen, M. Meistrich, and J. Xu. 2010. Jmjd1a demethylase-regulated histone modification is essential for cAMP-response element modulator-regulated gene expression and spermatogenesis. The Journal of biological chemistry. 285:2758-2770.

Luo, W., M.S. Friedman, K. Shedden, K.D. Hankenson, and P.J. Woolf. 2009. GAGE: generally applicable gene set enrichment for pathway analysis. BMC Bioinformatics. 10:161.

Macara, I.G. 2001. Transport into and out of the nucleus. Microbiol Mol Biol Rev. 65:570-594, table of contents.

Major, A.T., P.A. Whiley, and K.L. Loveland. 2011. Expression of nucleocytoplasmic transport machinery: clues to regulation of spermatogenic development. Biochim Biophys Acta. 1813:1668-1688.

Mali, P., A. Kaipia, M. Kangasniemi, J. Toppari, M. Sandberg, N.B. Hecht, and M. Parvinen. 1989. Stage-specific expression of nucleoprotein mRNAs during rat and mouse spermiogenesis. Reproduction, fertility, and development. 1:369-382.

Meng, J., A.R. Greenlee, C.J. Taub, and R.E. Braun. 2011. Sertoli cell-specific deletion of the androgen receptor compromises testicular immune privilege in mice. Biol Reprod. 85:254260. 
Meng, J., R.W. Holdcraft, J.E. Shima, M.D. Griswold, and R.E. Braun. 2005. Androgens regulate the permeability of the blood-testis barrier. Proc Natl Acad Sci U S A. 102:16696-16700.

Miyamoto, Y., P.R. Boag, G.R. Hime, and K.L. Loveland. 2012. Regulated nucleocytoplasmic transport during gametogenesis. Biochim Biophys Acta. 1819:616-630.

Nakauchi, H., K. Matsuda, I. Ochiai, A. Kawauchi, Y. Mizutani, T. Miki, and M. Kawata. 2007. A differential ligand-mediated response of green fluorescent protein-tagged androgen receptor in living prostate cancer and non-prostate cancer cell lines. J Histochem Cytochem. 55:535-544.

Namekawa, S.H., P.J. Park, L.F. Zhang, J.E. Shima, J.R. McCarrey, M.D. Griswold, and J.T. Lee. 2006. Postmeiotic sex chromatin in the male germline of mice. Current biology : CB. 16:660667.

Nantel, F., L. Monaco, N.S. Foulkes, D. Masquilier, M. LeMeur, K. Henriksen, A. Dierich, M. Parvinen, and P. Sassone-Corsi. 1996. Spermiogenesis deficiency and germ-cell apoptosis in CREM-mutant mice. Nature. 380:159-162.

Okada, Y., G. Scott, M.K. Ray, Y. Mishina, and Y. Zhang. 2007. Histone demethylase JHDM2A is critical for Tnp1 and Prm1 transcription and spermatogenesis. Nature. 450:119-123.

Orth, J.M., G.L. Gunsalus, and A.A. Lamperti. 1988. Evidence from Sertoli cell-depleted rats indicates that spermatid number in adults depends on numbers of Sertoli cells produced during perinatal development. Endocrinology. 122:787-794.

Pattabiraman, S., C. Baumann, D. Guisado, J.J. Eppig, J.C. Schimenti, and R. De La Fuente. 2015. Mouse BRWD1 is critical for spermatid postmeiotic transcription and female meiotic chromosome stability. J Cell Biol. 208:53-69.

Pelz, L., B. Purfurst, and F.G. Rathjen. 2017. The cell adhesion molecule BT-IgSF is essential for a functional blood-testis barrier and male fertility in mice. The Journal of biological chemistry. 292:21490-21503.

Peters, A.H., A.W. Plug, M.J. van Vugt, and P. de Boer. 1997. A drying-down technique for the spreading of mammalian meiocytes from the male and female germline. Chromosome Res. 5:66-68.

Pimentel, H., N.L. Bray, S. Puente, P. Melsted, and L. Pachter. 2017. Differential analysis of RNA-seq incorporating quantification uncertainty. Nat Methods. 14:687-690.

Ratan, R., D.A. Mason, B. Sinnot, D.S. Goldfarb, and R.J. Fleming. 2008. Drosophila importin alpha1 performs paralog-specific functions essential for gametogenesis. Genetics. 178:839-850.

Rother, F., T. Shmidt, E. Popova, A. Krivokharchenko, S. Hugel, L. Vilianovich, M. Ridders, K. Tenner, N. Alenina, M. Kohler, E. Hartmann, and M. Bader. 2011. Importin alpha7 is essential for zygotic genome activation and early mouse development. PLoS One. 6:e18310.

Russell, L.D. 1990. Histological and histopathological evaluation of the testis. Cache River Press, Clearwater, Fl.

Russell, L.D., and M.D. Griswold. 1993. The sertoli cell. Cache River Press Clearwater^ eFL FL.

Salzberg, Y., T. Eldar, O.D. Karminsky, S.B. Itach, S. Pietrokovski, and J. Don. 2010. Meig1 deficiency causes a severe defect in mouse spermatogenesis. Developmental biology. 338:158167.

Sassone-Corsi, P. 2002. Unique chromatin remodeling and transcriptional regulation in spermatogenesis. Science. 296:2176-2178.

Sato, H., and L.E. Maquat. 2009. Remodeling of the pioneer translation initiation complex involves translation and the karyopherin importin beta. Genes Dev. 23:2537-2550.

Shima, J.E., D.J. McLean, J.R. McCarrey, and M.D. Griswold. 2004. The murine testicular transcriptome: characterizing gene expression in the testis during the progression of spermatogenesis. Biol Reprod. 71:319-330.

Tejomurtula, J., K.B. Lee, S.K. Tripurani, G.W. Smith, and J. Yao. 2009. Role of importin alpha8, a new member of the importin alpha family of nuclear transport proteins, in early embryonic development in cattle. Biol Reprod. 81:333-342.

Thomas, M., N. Dadgar, A. Aphale, J.M. Harrell, R. Kunkel, W.B. Pratt, and A.P. Lieberman. 2004. Androgen receptor acetylation site mutations cause trafficking defects, misfolding, and aggregation similar to expanded glutamine tracts. The Journal of biological chemistry. 279:8389-8395. 
980

981

982

983

984

985

986

987

988

989

990

991

992

993

994

995

996

997

998

999

1000

1001

1002

1003

1004

1005

1006

1007

1008

1009

1010

1011

1012

1013

1014

1015

1016

1017

1018

1019

1020

1021

1022

1023

1024

1025

1026

1027

1028

1029

1030

1031

Tsuji, L., T. Takumi, N. Imamoto, and Y. Yoneda. 1997. Identification of novel homologues of mouse importin alpha, the alpha subunit of the nuclear pore-targeting complex, and their tissuespecific expression. FEBS Lett. 416:30-34.

Walker, W.H. 2010. Non-classical actions of testosterone and spermatogenesis. Philosophical transactions of the Royal Society of London. Series B, Biological sciences. 365:1557-1569.

Wen, Q., E.I. Tang, W.Y. Lui, W.M. Lee, C.K.C. Wong, B. Silvestrini, and C.Y. Cheng. 2018. Dynein 1 supports spermatid transport and spermiation during spermatogenesis in the rat testis. Am J Physiol Endocrinol Metab. 315:E924-E948.

Willems, A., S.R. Batlouni, A. Esnal, J.V. Swinnen, P.T. Saunders, R.M. Sharpe, L.R. Franca, K. De Gendt, and G. Verhoeven. 2010. Selective ablation of the androgen receptor in mouse sertoli cells affects sertoli cell maturation, barrier formation and cytoskeletal development. PLoS One. 5:e14168.

Wu, J.Y., T.J. Ribar, D.E. Cummings, K.A. Burton, G.S. McKnight, and A.R. Means. 2000. Spermiogenesis and exchange of basic nuclear proteins are impaired in male germ cells lacking Camk4. Nature genetics. 25:448-452.

Wu, Y., X. Hu, Z. Li, M. Wang, S. Li, X. Wang, X. Lin, S. Liao, Z. Zhang, X. Feng, S. Wang, X. Cui, Y. Wang, F. Gao, R.A. Hess, and C. Han. 2016. Transcription Factor RFX2 Is a Key Regulator of Mouse Spermiogenesis. Sci Rep. 6:20435.

Xiong, Z., C. Wang, Z. Wang, H. Dai, Q. Song, Z. Zou, B. Xiao, A.Z. Zhao, X. Bai, and Z. Chen. 2018. Raptor directs Sertoli cell cytoskeletal organization and polarity in the mouse testis. Biol Reprod. 99:1289-1302.

Yang, J., C.R. Morales, S. Medvedev, R.M. Schultz, and N.B. Hecht. 2007. In the absence of the mouse DNA/RNA-binding protein MSY2, messenger RNA instability leads to spermatogenic arrest. Biol Reprod. 76:48-54.

Yang, K., A. Meinhardt, B. Zhang, P. Grzmil, I.M. Adham, and S. Hoyer-Fender. 2012. The small heat shock protein ODF1/HSPB10 is essential for tight linkage of sperm head to tail and male fertility in mice. Mol Cell Biol. 32:216-225.

Yu, Y.E., Y. Zhang, E. Unni, C.R. Shirley, J.M. Deng, L.D. Russell, M.M. Weil, R.R. Behringer, and M.L. Meistrich. 2000. Abnormal spermatogenesis and reduced fertility in transition nuclear protein 1-deficient mice. Proc Natl Acad Sci U S A. 97:4683-4688.

Zhang, D., T.L. Penttila, P.L. Morris, M. Teichmann, and R.G. Roeder. 2001. Spermiogenesis deficiency in mice lacking the Trf2 gene. Science. 292:1153-1155.

Zhang, Z., X. Shen, D.R. Gude, B.M. Wilkinson, M.J. Justice, C.J. Flickinger, J.C. Herr, E.M. Eddy, and J.F. Strauss, 3rd. 2009. MEIG1 is essential for spermiogenesis in mice. Proc Natl Acad Sci U S A. 106:17055-17060.

Zhao, M., C.R. Shirley, S. Mounsey, and M.L. Meistrich. 2004. Nucleoprotein transitions during spermiogenesis in mice with transition nuclear protein Tnp1 and Tnp2 mutations. Biol Reprod. 71:1016-1025.

Zhao, M., C.R. Shirley, Y.E. Yu, B. Mohapatra, Y. Zhang, E. Unni, J.M. Deng, N.A. Arango, N.H. Terry, M.M. Weil, L.D. Russell, R.R. Behringer, and M.L. Meistrich. 2001. Targeted disruption of the transition protein 2 gene affects sperm chromatin structure and reduces fertility in mice. Mol Cell Biol. 21:7243-7255.

Zhou, H., I. Grubisic, K. Zheng, Y. He, P.J. Wang, T. Kaplan, and R. Tjian. 2013. Taf71 cooperates with Trf2 to regulate spermiogenesis. Proc Natl Acad Sci U S A. 110:16886-16891.

Zhou, Q., R. Nie, Y. Li, P. Friel, D. Mitchell, R.A. Hess, C. Small, and M.D. Griswold. 2008. Expression of stimulated by retinoic acid gene 8 (Stra8) in spermatogenic cells induced by retinoic acid: an in vivo study in vitamin A-sufficient postnatal murine testes. Biol Reprod. 79:35-42.

\section{Figure Legend}

Fig. 1 Disruption of importin $\alpha 7$ causes growth retardation and reduced testis size. (A) Gene targeting strategy for importin $\alpha 7^{\mathrm{\Delta IBB} / \Delta \mathrm{IBB}}$ and $\alpha 7^{-/-}$mice. In $\alpha 7^{\Delta \mathrm{IBB} / \Delta \mathrm{IBB}}$ mice, exon 2 is 
1032 replaced by a neomycin resistence $\left(\right.$ neo $\left.^{\mathrm{r}}\right)$ cassette with a polyadenylation site (pA). Since transcription does not always stop at $\mathrm{pA}$, a splicing variant is generated, carrying an in frame translational start site in exon 3. This results in the formation of a truncated protein lacking the IBB. In importin $\alpha 7^{-/-}$mice, a genetrap is located in intron 1, resulting in complete loss of the protein in most of the tissues. However, a testis-specific exon 1A (E1A) allows the generation of a germ cell- specific mRNA which in turn results in the generation of a full-length protein. (B) Western blot analysis of importin $\alpha 7$ expression in the testes of WT $\left(\alpha 7^{+/+}\right), \alpha 7^{\Delta \mathrm{IBB} / \Delta \mathrm{IBB}}$ and $\alpha 7^{-/-}$mice. The $58 \mathrm{kDa}$ full-length importin $\alpha 7$ protein is absent in the $\alpha 7^{\Delta \mathrm{IBB} / \Delta \mathrm{IBB}}$ testis, while it can be detected in both $\alpha 7^{-/-}$and WT testes (left panel). An importin $\alpha 7^{\Delta \mathrm{IBB}}$ protein which is about $10 \mathrm{kDa}$ smaller than the full-length importin $\alpha 7$ protein is found in the testis of $\alpha 7^{\mathrm{AIBB} / \Delta \mathrm{IBB}}$ mice (right panel). The antibody against the $\mathrm{N}$-terminus recognizes the full-length $\left(\alpha 7^{+/+}, \alpha 7^{-/-}\right.$

1043 ), but not the truncated $\left(\alpha 7^{\Delta \mathrm{IBB} / \Delta \mathrm{IBB}}\right)$ importin $\alpha 7$. The asterisks mark unspecific cross-reactions 1044 of the antibody. (C) RT-PCR of WT liver, WT testis and importin $\alpha 7^{-/-}$testis using primer pairs 1045 spanning different exons. In WT liver and testis, a transcript spanning exon1 and exon6 can be detected, while it is absent in $\alpha 7^{-/-}$testis. Only WT testis, but not WT liver expresses a specific transcript using an alternative exon (exon1A) and this transcript can be detected in $\alpha 7^{-/-}$mice as well, albeit to a lesser extent than in WT. As a control, all tested tissues express importin $\alpha 7$ transcripts spanning exon2 and exon6. (D) Relative body weight of WT, importin $\alpha 7^{\mathrm{AIBB} / \Delta \mathrm{IBB}}$ and $\alpha 7^{-/-}$mice at 4 days, and 2, 3, 5, 8-10, 15-16 weeks of age $\left(\alpha 7^{+/+}=1, n=6\right.$ per group). (E)

1051 Relative testis weight compared to body weight of adult WT $\left(\alpha 7^{+/+}\right)$, importin $\alpha 7^{\Delta \mathrm{IBB} / \Delta \mathrm{IBB}}$ and $\alpha 7^{-/-}$mice at $8-10$ weeks of age ( $n=6$ per group).

Fig. 2 Disruption of importin $\alpha 7$ causes oligozoospermia. (A) H\&E staining of paraffin embedded testis sections of adult WT $\left(\alpha 7^{+/+}\right)$, importin $\alpha 7^{\Delta \mathrm{IBB} / \Delta \mathrm{IBB}}$ and $\alpha 7^{-/ /}$mice (upper lane 20x; lower lane 40x magnification). (B) H\&E staining of epididymis sections of adult WT $\left(\alpha 7^{+/+}\right.$), importin $\alpha 7^{\Delta \mathrm{IBB} / \Delta \mathrm{IBB}}$ and $\alpha 7^{-/-}$mice. Upper lane: caput epididymidis (40x); lower lane: cauda epididymidis (20x, inserts 40x). Arrow heads in (A): multinucleated spermatid giant cells; arrows in (B): immature germ cells (upper lane), sloughed immature germ cells (lower lane). (C) Relative diameters of seminiferous tubules in importin $\alpha 7^{\Delta \mathrm{IBB} / \Delta \mathrm{IBB}}$ and $\alpha 7^{-/-}$mice compared to WT $\left(\alpha 7^{+/+}\right)$. (D) Epididymal sperm count of WT $\left(\alpha 7^{+/+}\right)$, importin $\alpha 7^{\Delta \mathrm{IBB} / \Delta \mathrm{IBB}}$ and $\alpha 7^{-/-}$mice $(n=4-6)$. (E) Representative images of epididymal sperms from WT $\left(\alpha 7^{+/+}\right)$, importin $\alpha 7^{\mathrm{AIBB} / \Delta \mathrm{IBB}}$ and $\alpha 7^{-/-}$mice. Scale bars: $100 \mu \mathrm{m}$. 
Fig. 3 Importin $\alpha 7$ is expressed in postmeiotic spermatids and Sertoli cells in WT testis.

(A) Immunohistochemistry of paraffin embedded WT testis sections using an antibody against the C-terminus of importin $\alpha 7$ (red), counterstained with DAPI (light blue) and peanut agglutinin (PNA), labelling the acrosome (green); 40x magnification. Scale bars: $25 \mu \mathrm{m}$. (B) Schematic image of importin $\alpha 7$ expressing cell types in mouse testis. S: nucleus of a Sertoli cell; eP: early pachytene spermatocyte; rs1: step 1 round spermatid; 13: step 13 sperm; P: pachytene spermatocyte; rs2-3: step 2-3 round spermatid; 14: step 14 sperm; rs4-6: step 4-6 round spermatid; 15: step 15 sperm; rs7-8: step 7-8 round spermatid; 16: step 16 sperm; Pl: preleptotene spermatocyte; L: leptotene spermatocyte; 9 . Step 9 elongating spermatid; L/Z spermatocytes at leptotene/zygotene transition; Z: zygotene spermatocyte; 10-11: step 10-11 elongating spermatid; 12: step 12 sperm; M: meiosis, SS: secondary spermatocyte; D: diakinesis spermatocyte; In: intermediate spermatogonium; B: type B spermatogonium.

Fig. 4 Importin $\alpha 7$ is expressed in developing germ cells, but not in Sertoli cells of importin $\boldsymbol{\alpha} 7^{-/-}$mice. (A) Immunohistochemistry of WT, importin $\alpha 7^{\Delta \mathrm{IBB} / \Delta \mathrm{IBB}}$ and $\alpha 7^{-/-}$testis paraffin sections using an antibody against the C-terminus of importin $\alpha 7$ showing selected stages of seminiferous tubules; importin $\alpha 7$ (red); DAPI (light blue); PNA (green); 40x magnification. (B) Immunohistochemistry of WT, importin $\alpha 7^{\mathrm{AIBB} / \Delta \mathrm{IBB}}$ and $\alpha 7^{-/-}$testis paraffin sections using an antibody against the N-terminus of importin $\alpha 7$ (red); counterstained with DAPI (blue). The protein is expressed in round and elongating spermatids, but not in Sertoli cells of importin $\alpha 7^{-}$ I- mice, while WT mice show a robust staining in Sertoli cells, indicated in the windows. Scale bars: $100 \mu \mathrm{m}$.

Fig. 5 Importin $\alpha 7$ deficiency decreases number of Sertoli cells and prevents nuclear

1090 import of AR. (A) Number of Sertoli cells per tubule of adult WT $\left(\alpha 7^{+/+}\right)$, importin $\alpha 7^{\mathrm{ABB} / \Delta \mathrm{IBB}}$ 1091 and $\alpha 7^{-/-}$testes. (B) Aberrant localization of Sertoli cells in seminiferous tubules of importin $\alpha 7^{\mathrm{AIBB} / \Delta \mathrm{IBB}}$ and $\alpha 7^{-/-}$testes. (C) Immunofluorescence staining of testis section against AR (red), counterstain with DAPI (light blue). Arrows mark the typical nuclei of Sertoli cells with positive signal of AR; note the nuclear localization of AR in WT and the empty nuclei in importin $\alpha 7^{\mathrm{AIBB} / \Delta \mathrm{IBB}}$ and $\alpha 7^{-/-}$. (D) Relative expression levels of selected genes in testes of adult

$1096 \mathrm{WT}\left(\alpha 7^{+/+}\right)$, importin $\alpha 7^{\mathrm{AIBB} / \Delta \mathrm{IBB}}$ and $\alpha 7^{-/-}$testes $(\mathrm{n}=6)$. (E) Cldn3 (red) and DAPI (blue) staining 1097 on paraffin sections of adult WT $\left(\alpha 7^{+/+}\right)$, importin $\alpha 7^{\mathrm{ABBB} / \Delta \mathrm{IBB}}$ and $\alpha 7^{-/-}$testes. Arrows mark 1098 Cldn3 staining of stage VIII seminiferous tubuli. Scale bars: $100 \mu \mathrm{m}$. 
1100 Fig. 6 Compromised BTB and Sertoli cell function in importin $\alpha 7$-deficient testis. (A) ZO-

11011 (red) and DAPI (light blue) staining of testis paraffin sections of WT $\left(\alpha 7^{+/+}\right)$, importin $1102 \alpha 7^{\triangle \mathrm{IBB} / \Delta \mathrm{IBB}}$ and $\alpha 7^{-/-}$mice. Scale bars: $100 \mu \mathrm{m}$. (B) Western blot analysis of protein extracts 1103 prepared from the testes of WT mice probed with sera from WT $\left(\alpha 7^{+/+}\right)$, importin $\alpha 7^{\Delta \mathrm{IBB} / \Delta \mathrm{IBB}}$ 1104 and $\alpha 7^{-/-}$mice at 16 weeks of age. Lines mark 20-, 50- and 75-kDa testicular antigens recognized 1105 by antibodies (autoantibodies) present in serum samples of different importin $\alpha 7^{\triangle \mathrm{IBB} / \triangle \mathrm{IBB}}$ and $1106 \alpha 7^{-/-}$but not WT males. (C) Representative western blot of immunoglobulins in testis extracts 1107 of importin $\alpha 7^{+/+}, \alpha 7^{\Delta \mathrm{IBB} / \Delta \mathrm{IBB}}$ and $\alpha 7^{-/-}$mice of different ages. (D) Biotin diffusion assay to test 1108 the integrity of the BTB. Biotin is visualized by streptavidin-Cy5 staining (red). Importin $1109 \alpha 7^{\triangle \mathrm{IBB} / \Delta \mathrm{IBB}}$ and $\alpha 7^{-/-}$tubules show no major changes of biotin distribution compared to importin $1110 \alpha 7^{+/+}$seminiferous tubules. As a control, a BT-IgSF knockout mouse was analyzed, which has 1111 recently been published to show a severe disruption of the BTB (Pelz et al., 2017). Scale bars: $1112100 \mu \mathrm{m}$. (E) Vimentin (red) and DAPI (light blue) staining in testis paraffin sections of WT $1113\left(\alpha 7^{+/+}\right)$, importin $\alpha 7^{\mathrm{ABBB} / \Delta \mathrm{IBB}}$ and $\alpha 7^{-/-}$mice; scale bars: $100 \mu \mathrm{m}$. (F) H\&E staining of testis 1114 paraffin sections showing aberrant sperm orientation in seminiferous tubules of importin $1115 \alpha 7^{\triangle \mathrm{IBB} / \Delta \mathrm{IBB}}$ and $\alpha 7^{-/-}$testes. Arrows mark the misorientated sperms. (G) DAPI and PNA staining 1116 in testis paraffin sections of WT $\left(\alpha 7^{+/+}\right)$, importin $\alpha 7^{\Delta \mathrm{IBB} / \Delta \mathrm{IBB}}$ and $\alpha 7^{-/-}$mice showing defective 1117 sperm transport through the seminiferous epithelium in importin $\alpha 7^{\Delta \mathrm{IBB} / \Delta \mathrm{IBB}}$ testes. Arrows 1118 mark the mislocalized sperms. (H) Sperm retention in stage IX seminiferous tubules. To label 1119 sperm cells, immunohistochemistry using anti-acetyl-Histone H4 (H4K8Ac, green), PNA (red) 1120 and DAPI (light blue) was performed. Asterisks indicate sperm retention. Scale bars: $25 \mu \mathrm{m}$.

Fig. 7 Importin $\alpha 7$ deficiency results in a loss of spermatocytes. (A) Number of 1123 spermatogonia, preleptotene, leptotene/zygotene, pachytene spermatocytes and round 1124 spermatids per seminiferous tubule in adult WT $\left(\alpha 7^{+/+}\right)$, importin $\alpha 7^{\Delta \mathrm{IBB} / \Delta \mathrm{IBB}}$ and $\alpha 7^{-/-}$testes. (B) $1125 \gamma \mathrm{H} 2 \mathrm{AX}\left(\right.$ red) and DAPI (light blue) staining in adult WT, importin $\alpha 7^{\Delta \mathrm{IBB} / \Delta \mathrm{IBB}}$ and $\alpha 7^{-/-}$testes. 1126 X-XI: stage X-XI tubuli, scale bars: $100 \mu \mathrm{m}$.

1128 Fig. 8 Importin $\alpha 7$ deficiency causes a delay in the first spermatogenesis wave. (A) $H \& E$ 1129 staining of testis paraffin sections of WT $\left(\alpha 7^{+/+}\right)$, importin $\alpha 7^{\mathrm{\Delta IBB} / \Delta \mathrm{IBB}}$ and $\alpha 7^{-/-}$at 6 weeks of 1130 age showing severely delayed onset of spermatogenesis. (B) BrdU (red), $\gamma \mathrm{H} 2 \mathrm{AX}$ (green) and 1131 DAPI (blue) staining on paraffin sections of day $14 \mathrm{WT}\left(\alpha 7^{+/+}\right)$and importin $\alpha 7^{\mathrm{ABB} / \Delta \mathrm{IBB}}$ testes. 1132 The yellow colour indicates colocalization of BrdU and $\gamma \mathrm{H} 2 \mathrm{AX}(\mathrm{C}) \gamma \mathrm{H} 2 \mathrm{AX}(\mathrm{red})$ and DAPI 
1133 (blue) staining on paraffin sections of day $21 \mathrm{WT}$ and importin $\alpha 7^{\Delta \mathrm{IBB} / \Delta \mathrm{IBB}}$ testes. B: B 1134 spermatogonia; $\mathrm{pL}$ : preleptotene spermatocytes; L/Z: spermatocytes at leptotene to zygotene 1135 transition; eP: early pachytene spermatocytes; P: pachytene spermatocytes; rs: round 1136 spermatids. Scale bars: $100 \mu \mathrm{m}$.

Fig. 9 Downregulated spermiogenesis-related pathways in importin $\alpha$ 7-deficient testis. (A) Volcano plot depicting the differential gene regulation of the testes transcriptomes of WT and importin $\alpha 7^{\mathrm{AIBB} / \Delta \mathrm{IBB}}$ mice. The $\mathrm{x}$ - and the $\mathrm{y}$-axes show the effect size according to a Wald test and the negative $\log _{10}$ transformed p-value. Small red dots indicate significantly regulated genes according to the $\mathrm{p}$-value $(\mathrm{p}<0.01)$ and the absolute effect size $(>1)$. The Kpna6 gene is indicated

1143 by an enlarged red circle. (B) Dotplot depicting the 20 most significantly up- and downregulated

$1144 \mathrm{GO}$ terms in the testes transcriptomes of importin $\alpha 7^{\mathrm{AIBB} / \Delta \mathrm{IBB}}$ mice compared to WT. The locus and color of the dots indicates the $-\log _{10} \mathrm{p}$-value, while the dot size is related to the number of genes of the GO term. Blue and black row names refer to the down- and upregulated GO terms, respectively. (C) Volcano plot depicting the predicted differential TF activity of the testis transcriptomes of WT and importin $\alpha 7^{\triangle \mathrm{IBB} / \Delta \mathrm{IBB}}$ mice. The $\mathrm{x}$ - and the $\mathrm{y}$-axes show the t-statistic of a t-test and the negative $\log _{10}$ transformed p-value. Red dots indicate significant differential TF activity according to the $\mathrm{p}$-value $(\mathrm{p}<0.01)$ and the absolute t-statistic. (D) Venn diagramm showing the commonly and individually up- and downregulated genes from mouse testes in a $\mathrm{Rf} 22 \mathrm{KO}$ and the importin $\alpha 7^{\mathrm{\triangle IBB} / \triangle \mathrm{IBB}}$ model in comparison to their respective wildtype controls. P-value cutoff $<0.01$, absolute effect size $>0.5$. (E) Barplot depicting simultaneously the significance of 23 most downregulated GO terms in testes transcriptomes after importin $\alpha 7$ depletion (Kpna6, red) or Rfx2 knockdown (GEO ID GSE68283) (Rfx2, green) according to a gene set enrichment analysis. The bars denote the $-\log _{10}$ transformed $\mathrm{p}$-values.

Fig. 10 Importin $\alpha 7$-deficient spermatids show abnormal elongation and nuclear condensation. Morphology of DAPI- (blue) and PNA- (red) labelled spermatids throughout their development starting with elongation (step9). The deficiency/delay in elongation can be seen already in stage XII tubuli. Note the abnormal configuration of sperm heads in importin $\alpha 7^{\mathrm{AIBB} / \Delta \mathrm{IBB}}$ spermatids. postmeiotic genes including protamines and transition nuclear proteins in isolated round 
1167 spermatids of adult WT $\left(\alpha 7^{+/+}\right)$and importin $\alpha 7^{\mathrm{AIBB} / \Delta \mathrm{IBB}}$ testes (n=3-9). (B) Western blot 1168 analysis of Tnp2 in WT $\left(\alpha 7^{+/+}\right)$and importin $\alpha 7^{\Delta \mathrm{IBB} / \Delta \mathrm{IBB}}$ testis protein extracts. (C, D) Tnp1 (C, 1169 red), Tnp2 (D, red) and DAPI (light blue) staining on testis paraffin sections of adult WT and 1170 importin $\alpha 7^{\mathrm{AIBB} / \Delta \mathrm{IBB}}$ testes. Roman numbers mark the stage of seminiferous tubules; scale bars: $1171 \quad 100 \mu \mathrm{m}$.

Fig. 12 Disturbed expression of transcriptional regulator Brwd1 in importin $\alpha 7$-deficient testes (A, B) Immunofluorescence for Brwd1 (red) in importin $\alpha 7^{+/+}$and $\alpha 7^{\mathrm{AIBB} / \Delta \mathrm{IBB}}$ testis on paraffin sections (A) or on snap-frozen cryosections (B); counterstain with DAPI (light blue), scale bars: $100 \mu \mathrm{m}$.

Fig. S1 (A) Epididymal sperm count of all homozygous and heterozygous mutant lines including compound heterozygous mice $\left(\alpha 7^{\Delta \mathrm{IBB} /}\right)$ compared to WT mice $(n=4-6)$. (B) Western blot analysis of testis protein extracts with $\mathrm{N}$-terminal and $\mathrm{C}$-terminal anti-importin $\alpha 7$ antibodies show, that $\alpha 7^{\Delta \mathrm{IBB} /-}$ testes express both, the full-length and the truncated protein.

Fig. S2 Principal component analysis of the gene-aggregated expression values as measured in transcipts per million of the $50 \%$ most variable genes across all samples.

Fig. S3 Immunofluorescence for Crem (green) in importin $\alpha 7^{+/+}$and importin $\alpha 7^{\Delta \mathrm{IBB} / \Delta \mathrm{IBB}}$ testis. For staging of seminiferous tubules, testis paraffin sections were stained with DAPI (blue) and lectin peanut agglutinin (PNA-A1594, red, merge, right panel). Scale bars: $25 \mu \mathrm{m}$.

Table S1 List of antibodies with respective conditions they were used in.

Table S2 List of primer sequences of target genes.

Table S3 Differential gene expression in importin $\alpha 7^{\mathrm{\Delta IBB} / \Delta \mathrm{IBB}}$ and importin $\alpha 7^{-/-}$testes compared to WT and to each other.

1197 Table S4 List of genes, which are differentially expressed in testis of Rfx2 KO and importin $1198 \alpha 7^{\Delta \mathrm{IBB} / \Delta \mathrm{IBB}}$ compared to their respective WT controls (P-value cutoff $<0.01$, absolute effect size $1199>0.5)$. 
bioRxiv preprint doi: https://doi.org/10.1101/2020.11.09.374652; this version posted November 9, 2020. The copyright holder for this

preprint (which was not certified by peer review) is the author/funder. All rights reserved. No reuse allowed without permission.

1201 Table S5 Gene Set Enrichment Analysis of importin $\alpha 7^{\mathrm{AIBB} / \Delta \mathrm{IBB}}$ and Rfx2 knockout testes. 
Fig. 1

A

importin $\alpha 7^{+/+}$

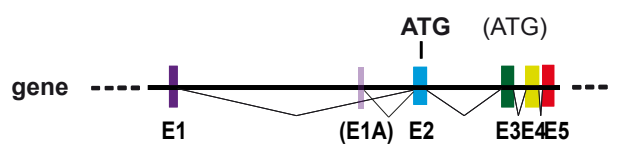

transcription

mRNA

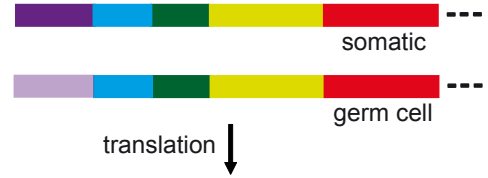

protein

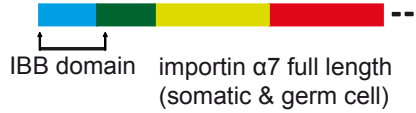

importin $\alpha 7^{\mathrm{AlBB} / \Delta \mathrm{IBB}}$

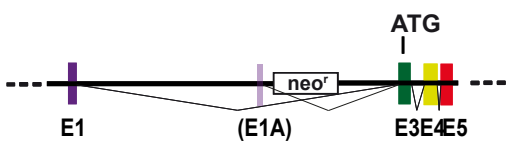

transcription \\& alternative splicing

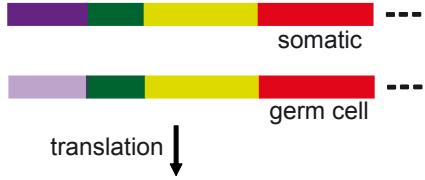

truncated importin $\alpha 7$ (somatic \& germ cell) importin $\alpha 7^{--}$

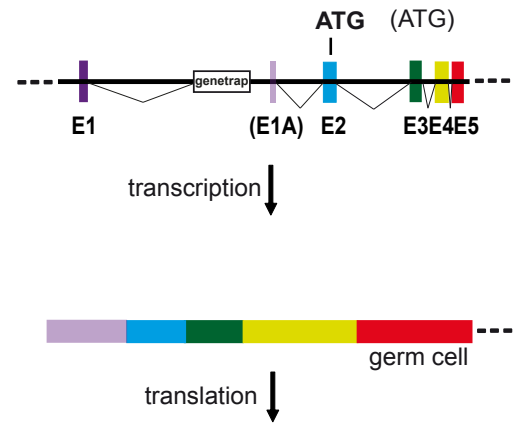

IBB domain importin $\alpha 7$ full length (only germ cell)
B

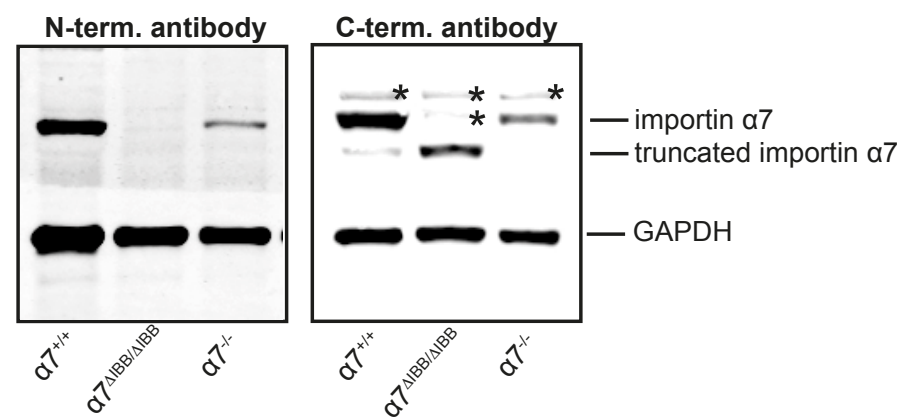

D

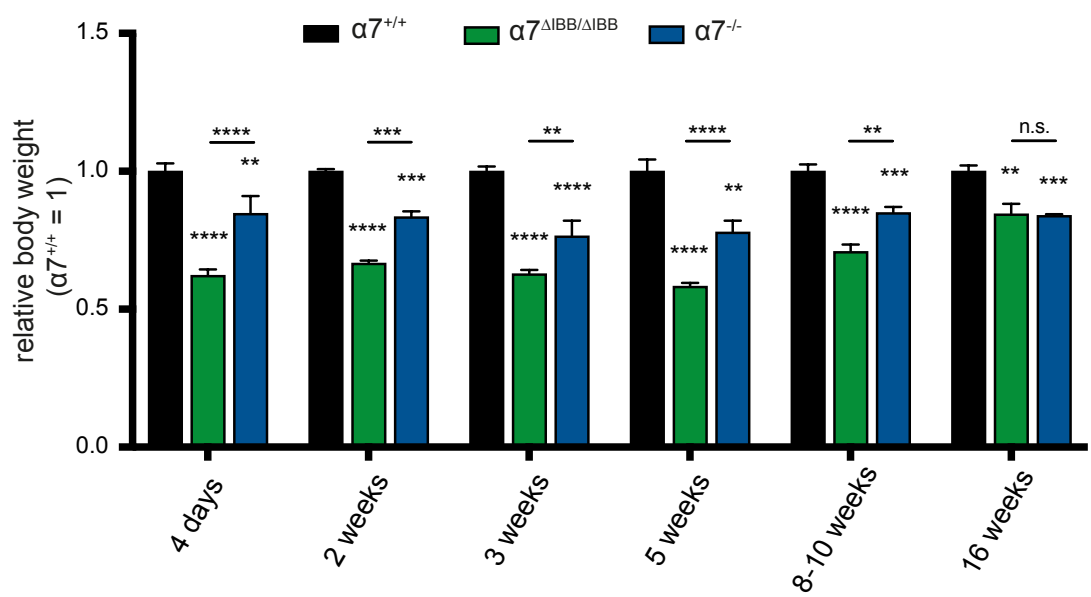

C

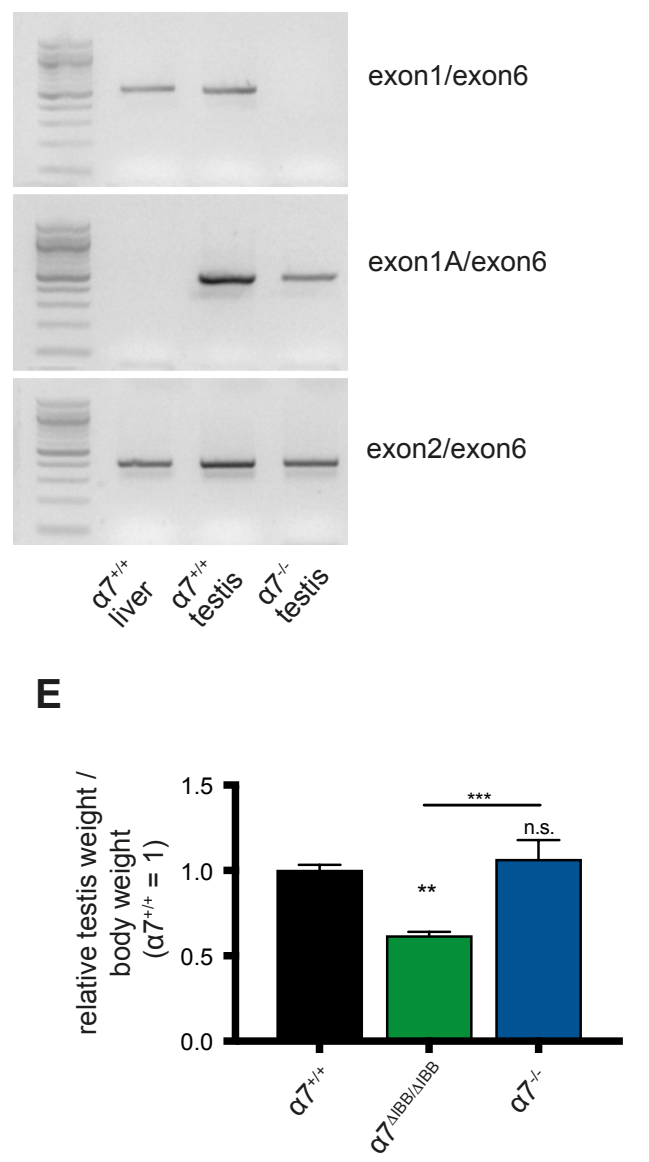


Fig. 2
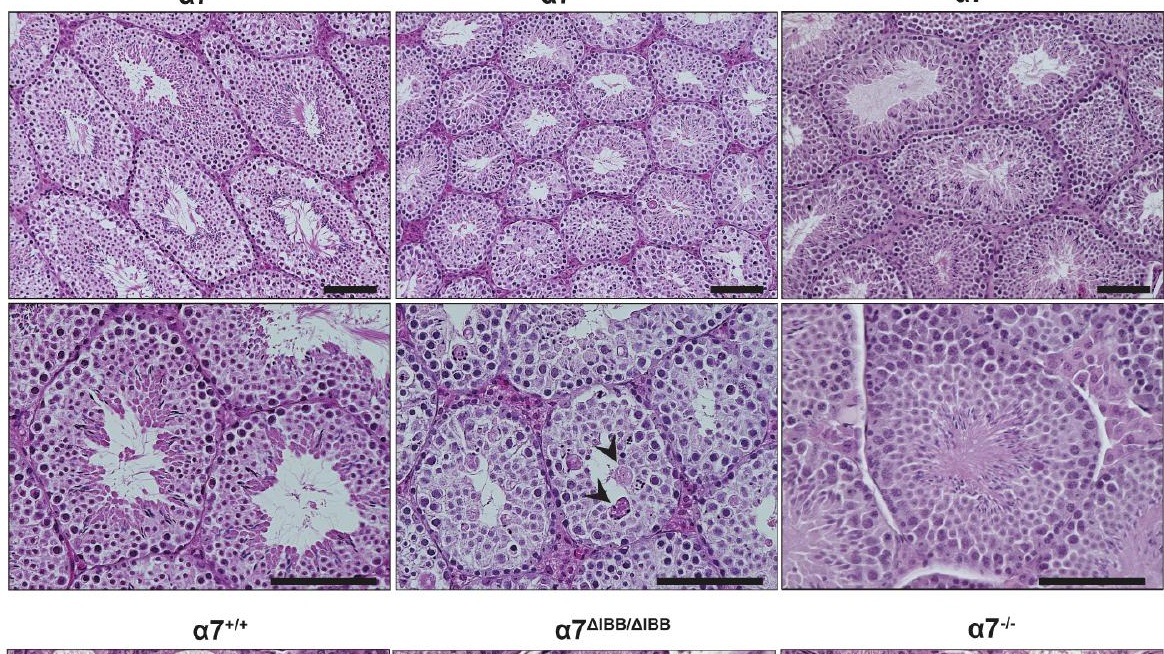

B
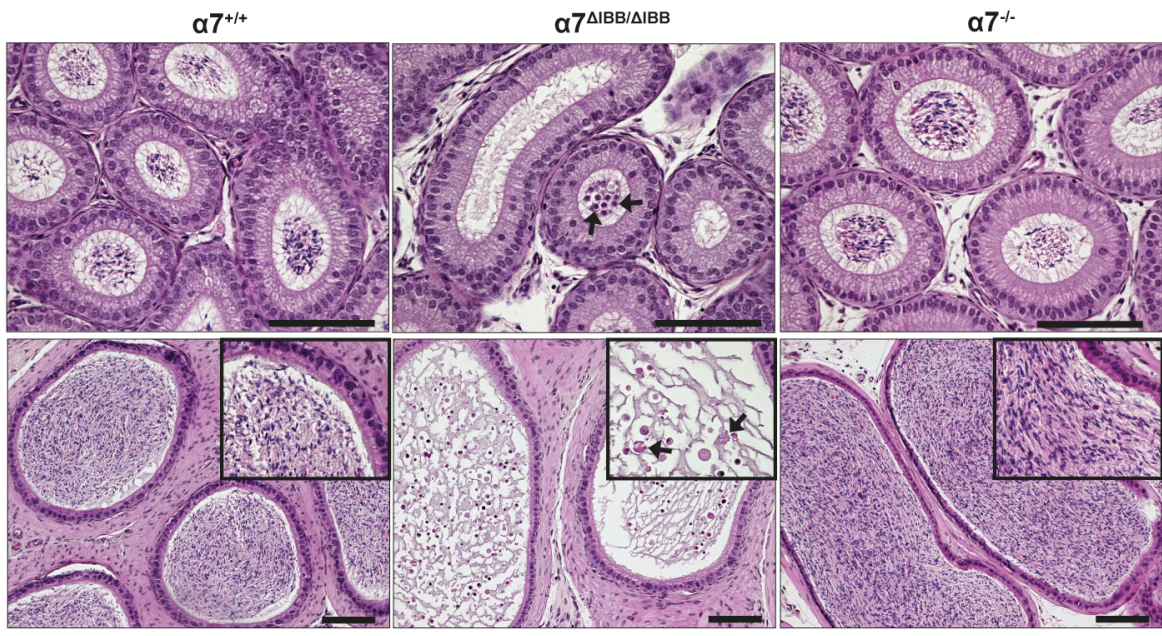

C

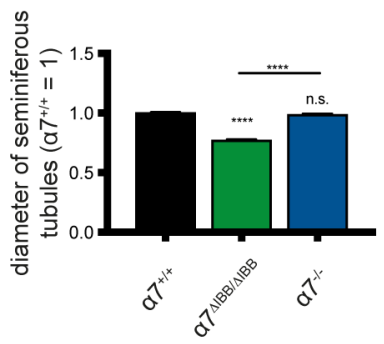

E
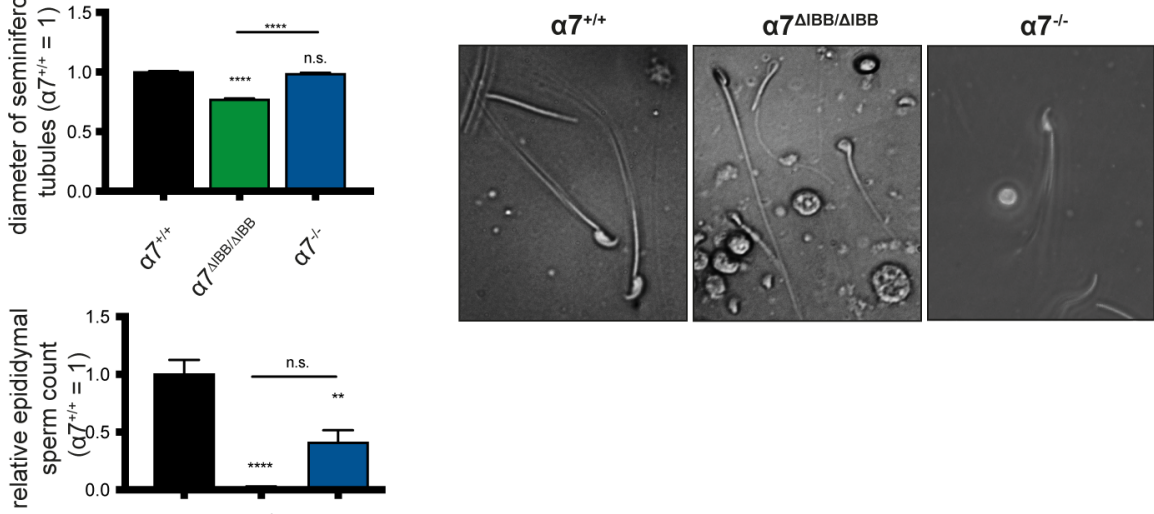

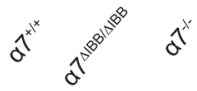



Fig. 5

A

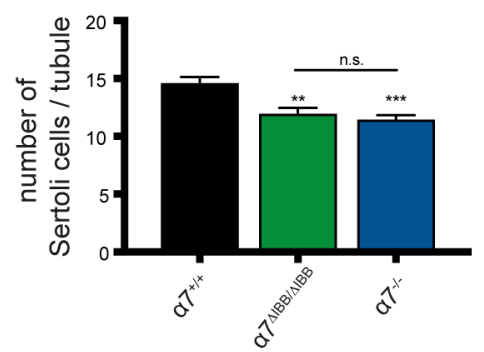

B

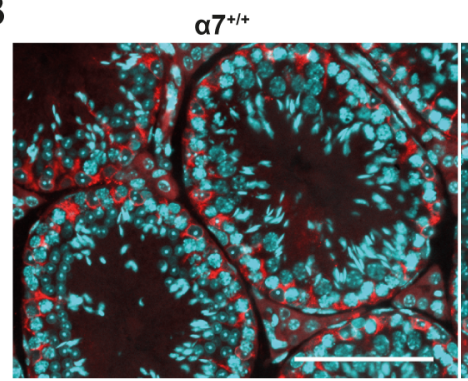

D

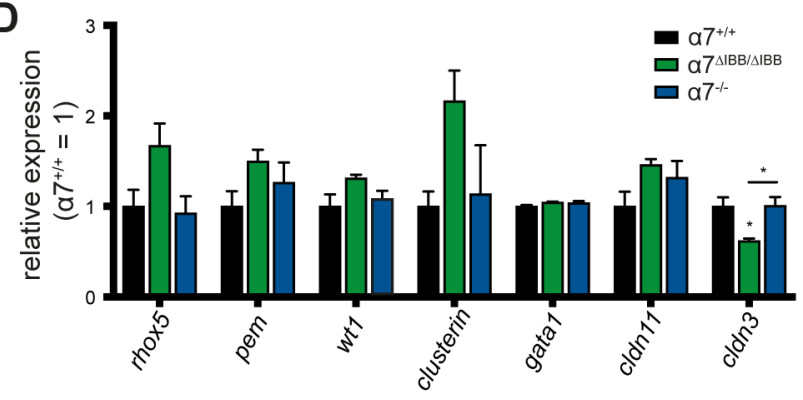

$\alpha 7^{\mathrm{AlBB} / \mathrm{AlBB}}$

$\alpha 7^{-1-}$
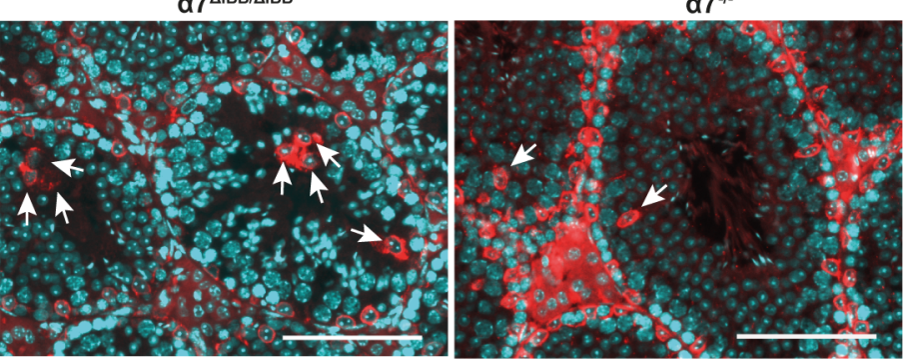

$\alpha 7^{+/+}$

$\alpha 7^{\mathrm{AlBB} / \Delta \mathrm{IBB}}$

$\alpha 7^{-1-}$
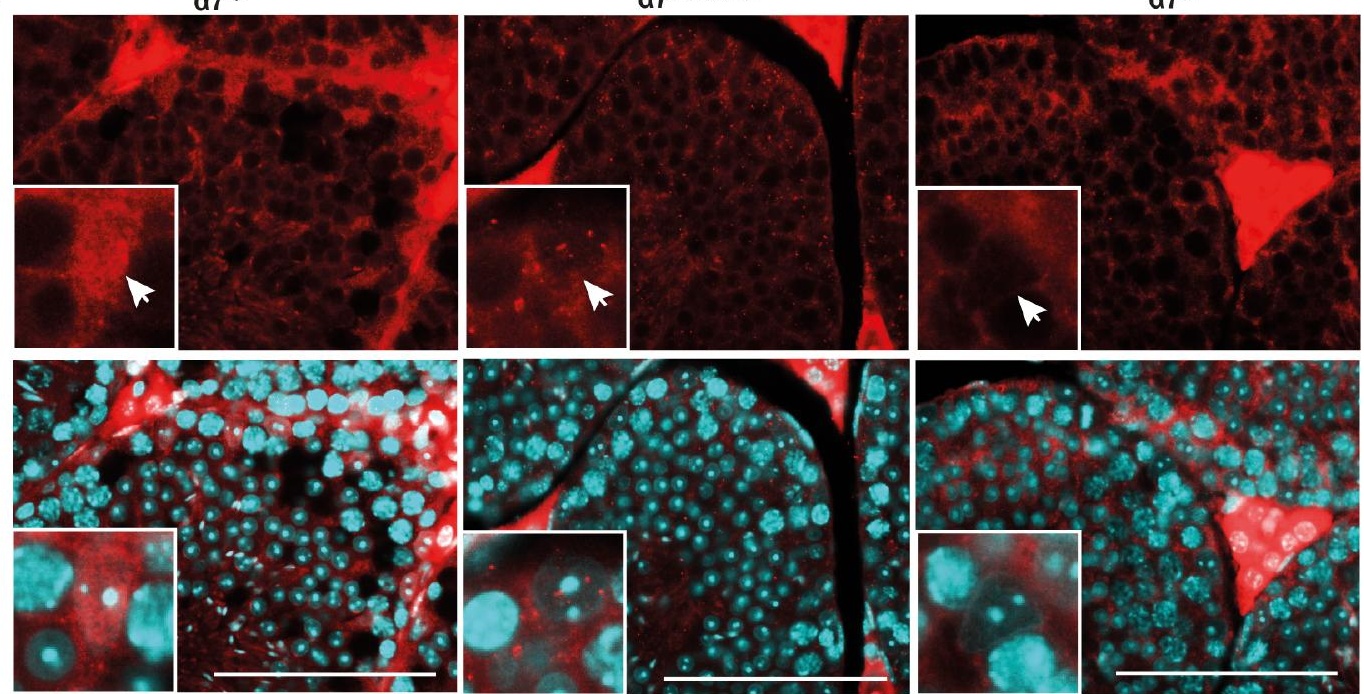

Androgen receptor DAPI

$\mathbf{E}$

$\alpha 7^{+/+}$

$\alpha 7^{\mathrm{AIBB} / \Delta \mathrm{IBB}}$

$\alpha 7^{-/-}$ 
Fig. 6

A

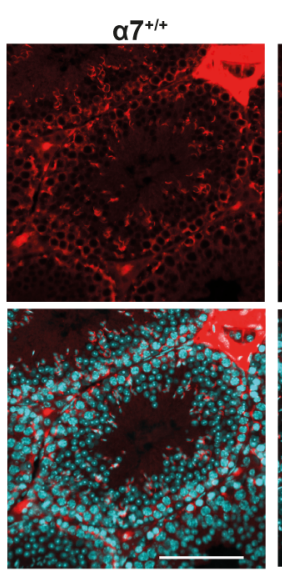

E
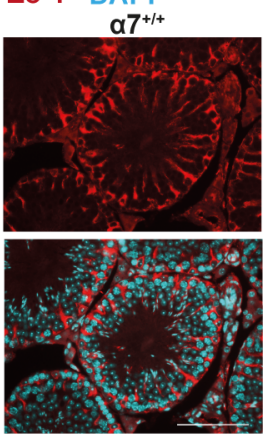

Vimentin DAPI

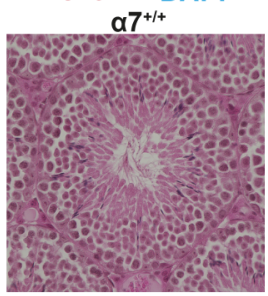

G

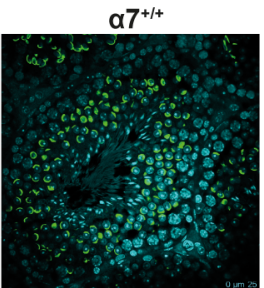

PNA DAPI
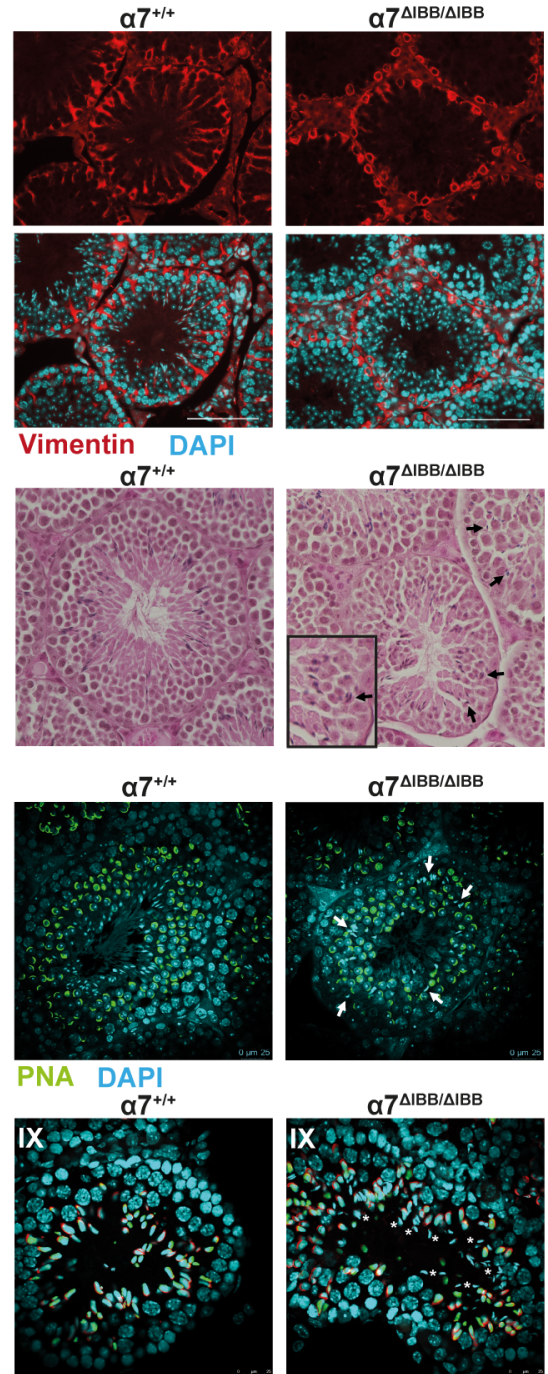

$\alpha 7^{\mathrm{AlBB} / \Delta \mathrm{IBB}}$
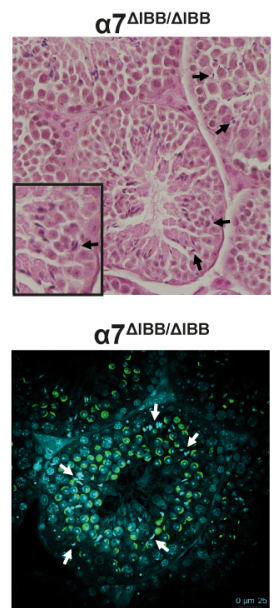

$\alpha 7^{\mathrm{AlBB} / \mathrm{AlBB}}$

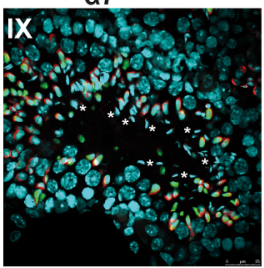

$\alpha 7^{-1-}$

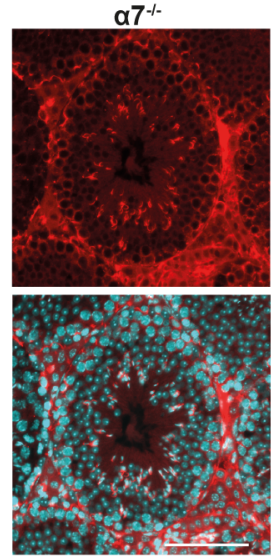

$\alpha 7^{-1-}$
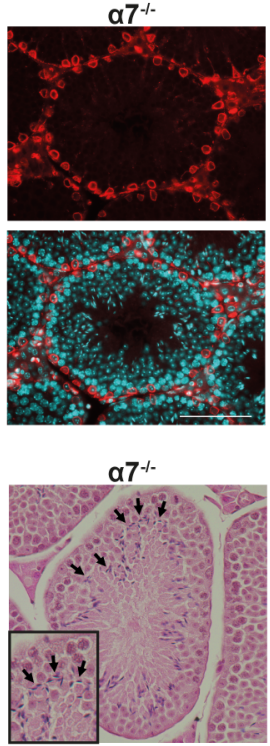

$\alpha 7^{-1-}$

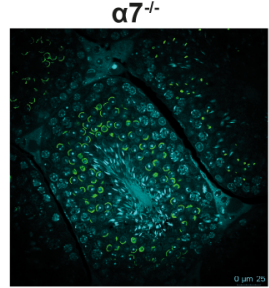

$\alpha 7^{-1-}$

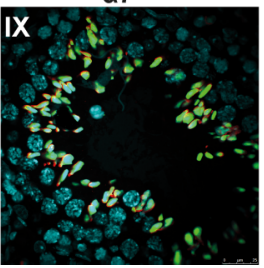

B

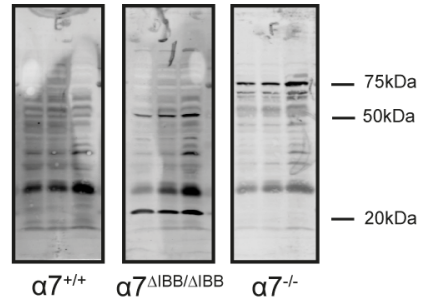

C

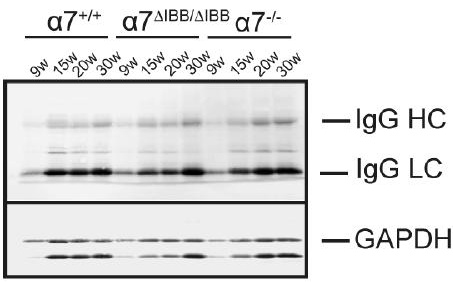

D

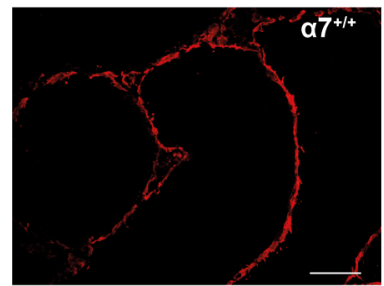

$\alpha 7^{\mathrm{AlBB} / \triangle \mathrm{IBB}}$
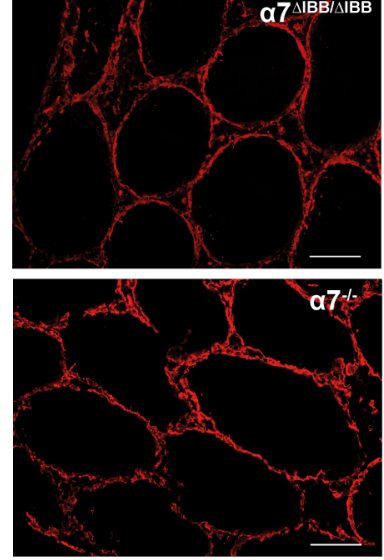

BT-IgSF 
Fig. 7

A

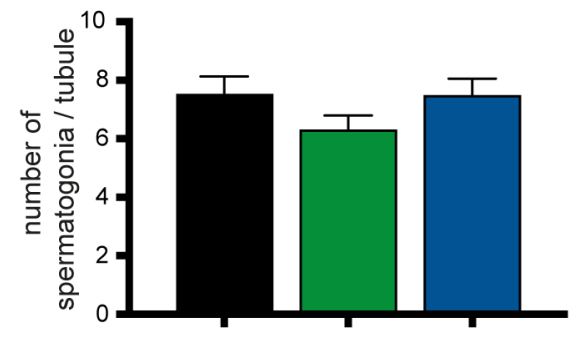

수

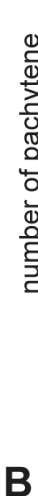

$\hat{0}^{x^{*}} \quad \hat{0}^{x^{x^{3}}}$ a

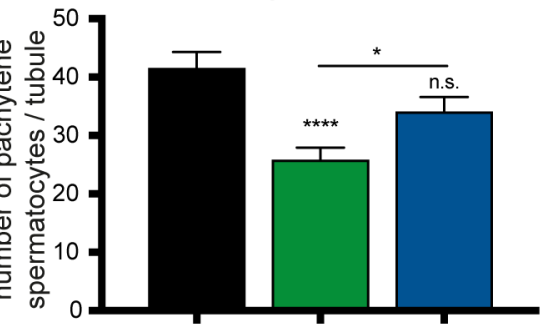

B

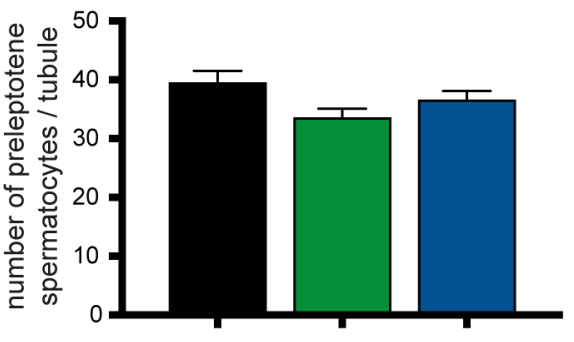

$\hat{a}^{x^{*}}$

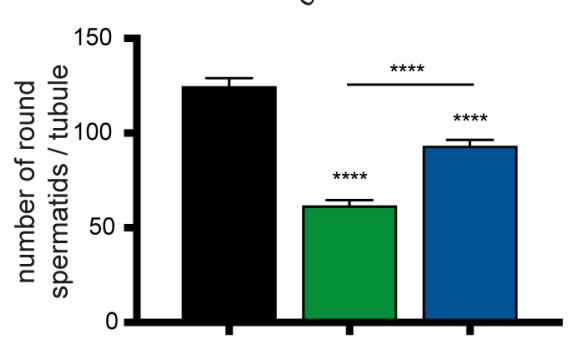

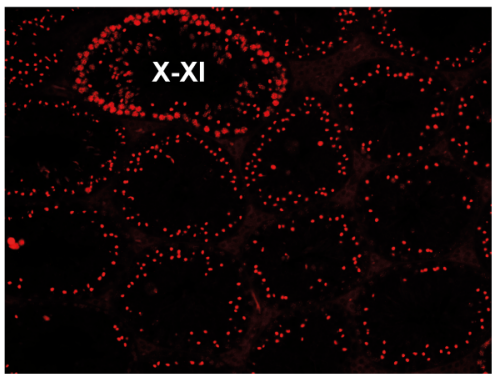
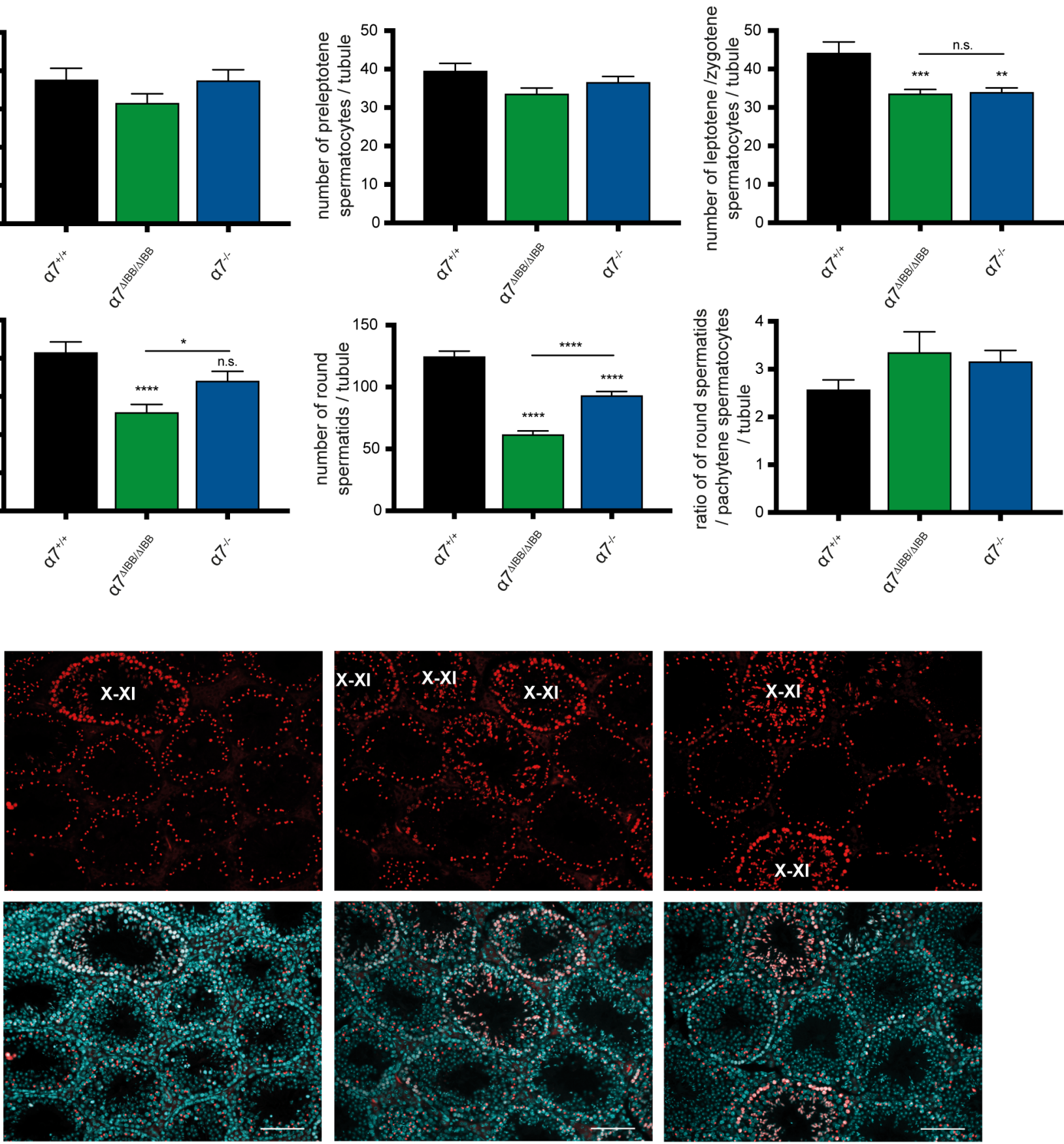

$\gamma$ H2ax

DAPI

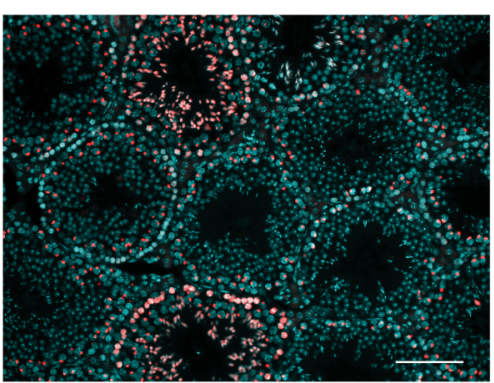

$\frac{1}{2 x^{2}}$ 
Fig. 8
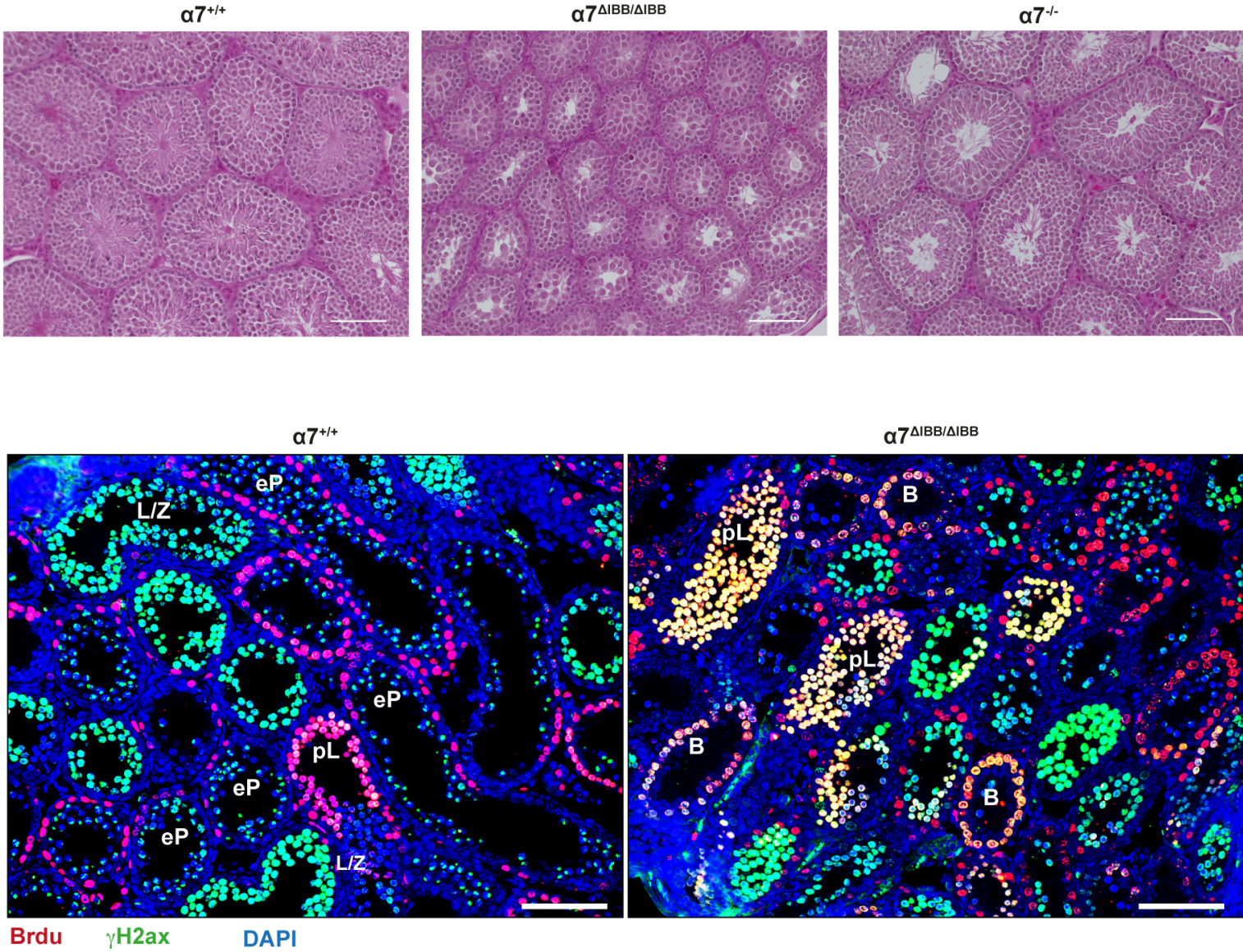

$\alpha 7^{+1+}$

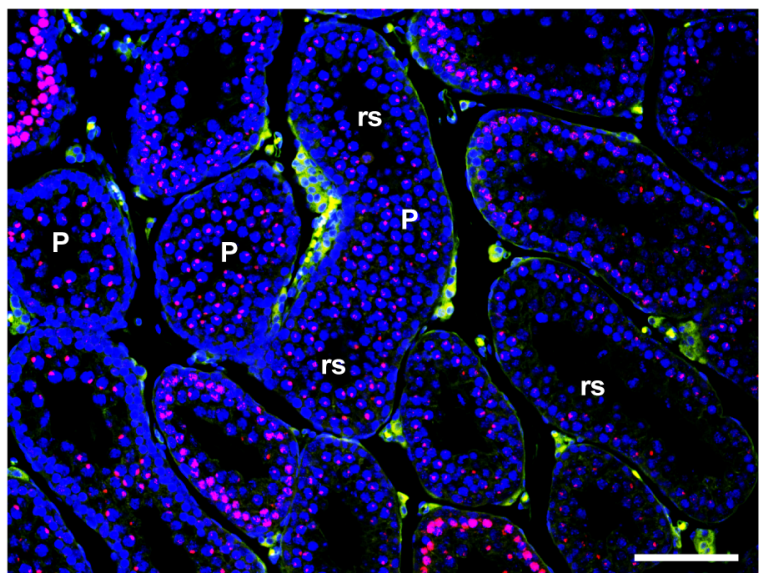

$\alpha 7^{\Delta \mathrm{lBB} / \Delta \mathrm{lBB}}$

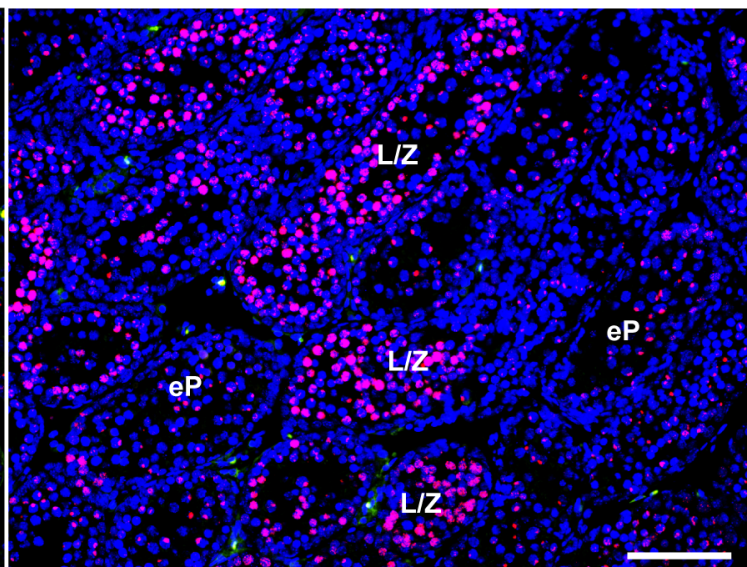


Fig. 9

A

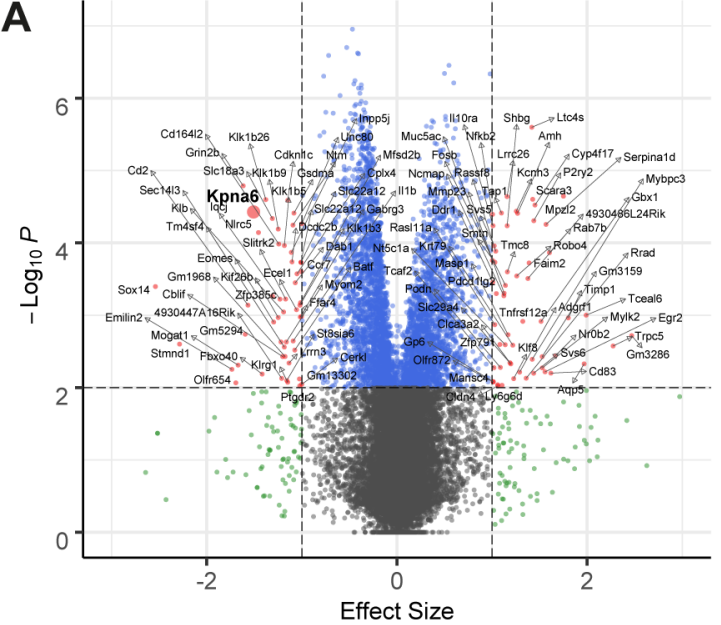

C

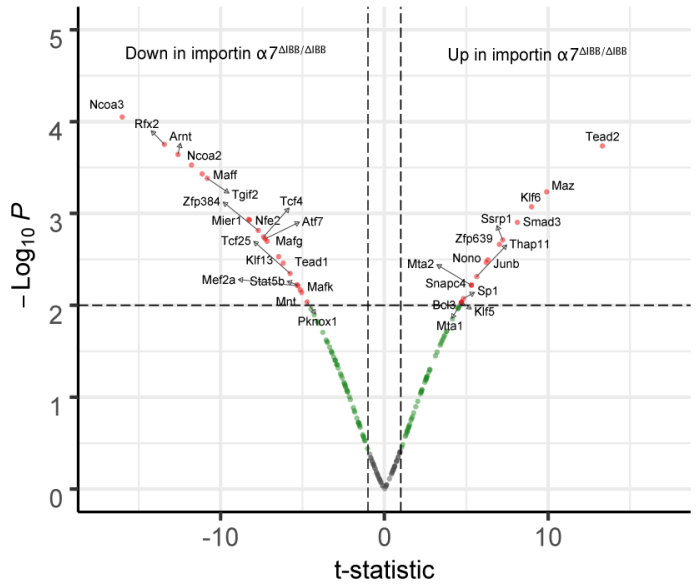

B

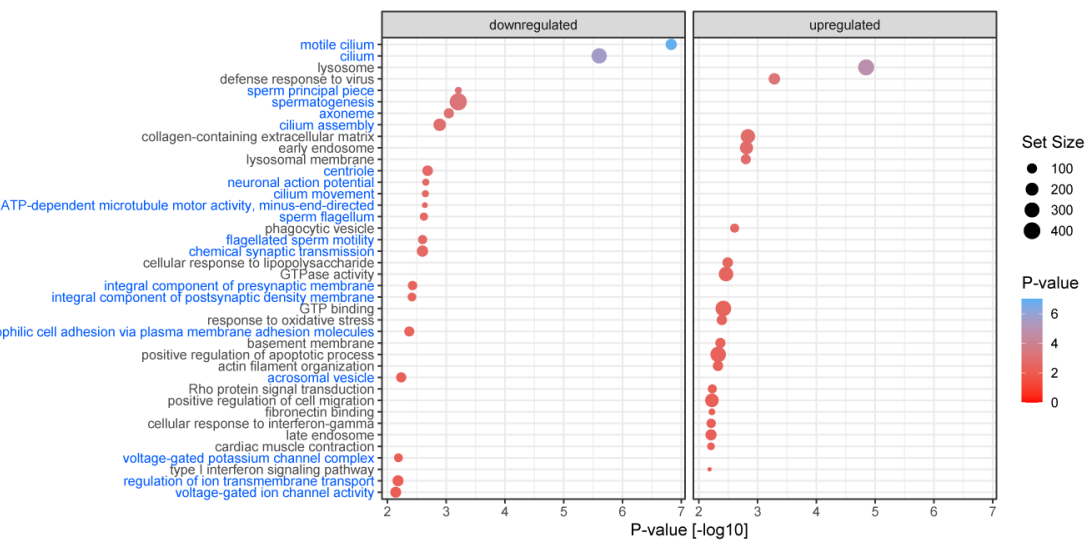

D

Rfx2 KO

up: 317

32

456

down: 920

88

219
E

\section{Kpna6 KO}
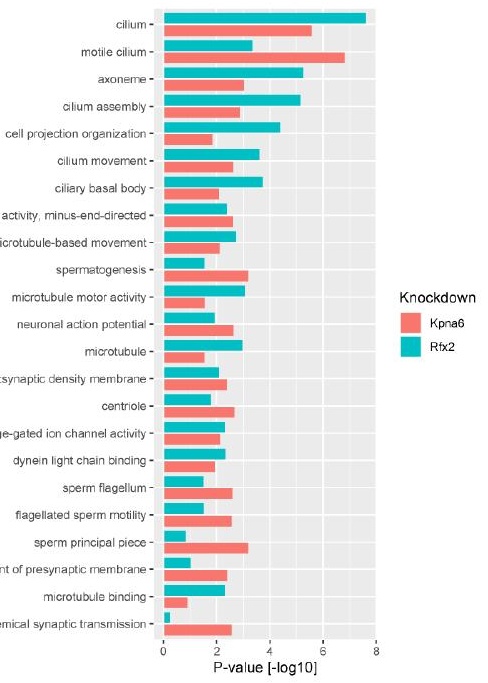
Fig. 10
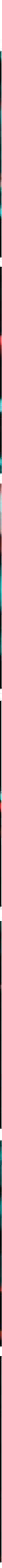

PNA 
Fig. 11

A
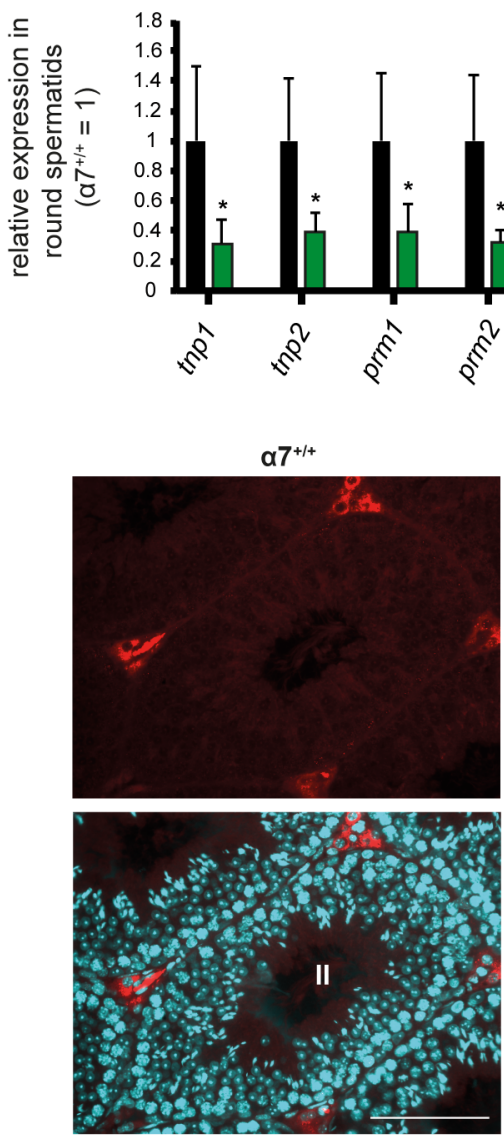

Tnp1

$\alpha 7^{+/+}$
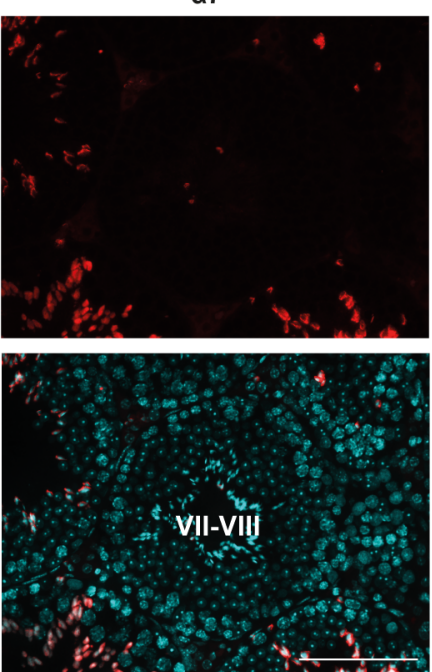

Tnp2
- $\alpha 7^{+/+}$

$=\alpha 7^{\triangle \mathrm{BB} / \triangle \mathrm{BB}}$

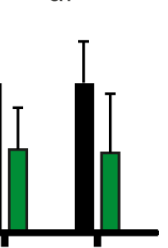

$\underbrace{2}$

$0^{x}$

हैं की

$\alpha 7^{\mathrm{AlBB} / \triangle \mathrm{BBB}}$
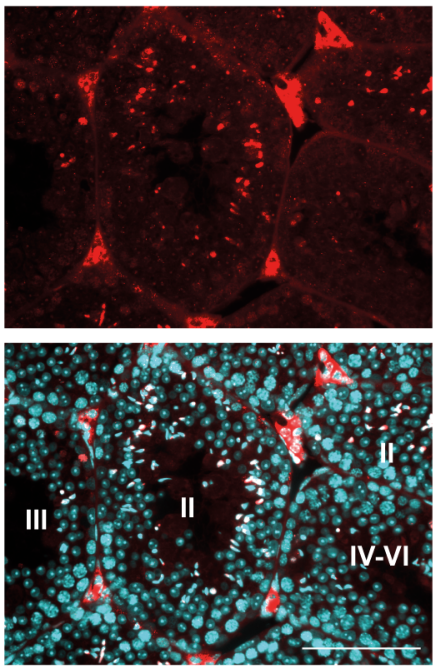

$\alpha 7^{\mathrm{\Delta lBB} / \mathrm{BlBB}}$
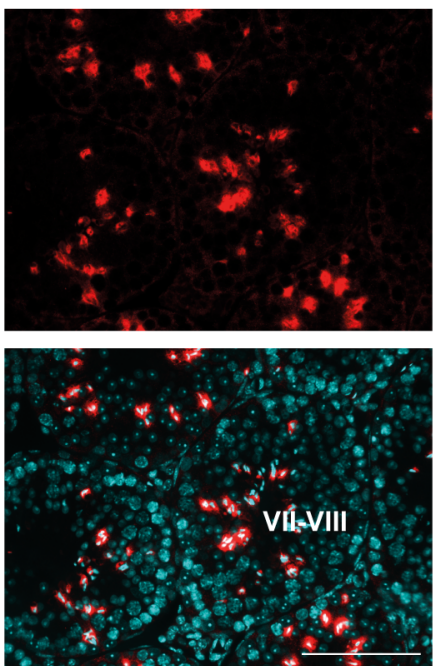

B
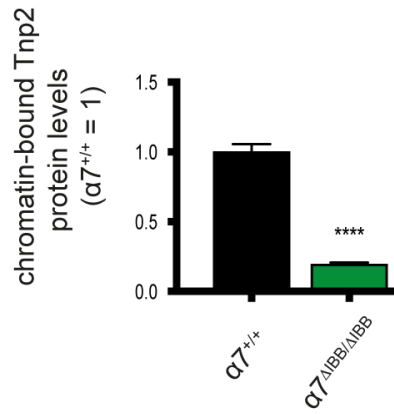

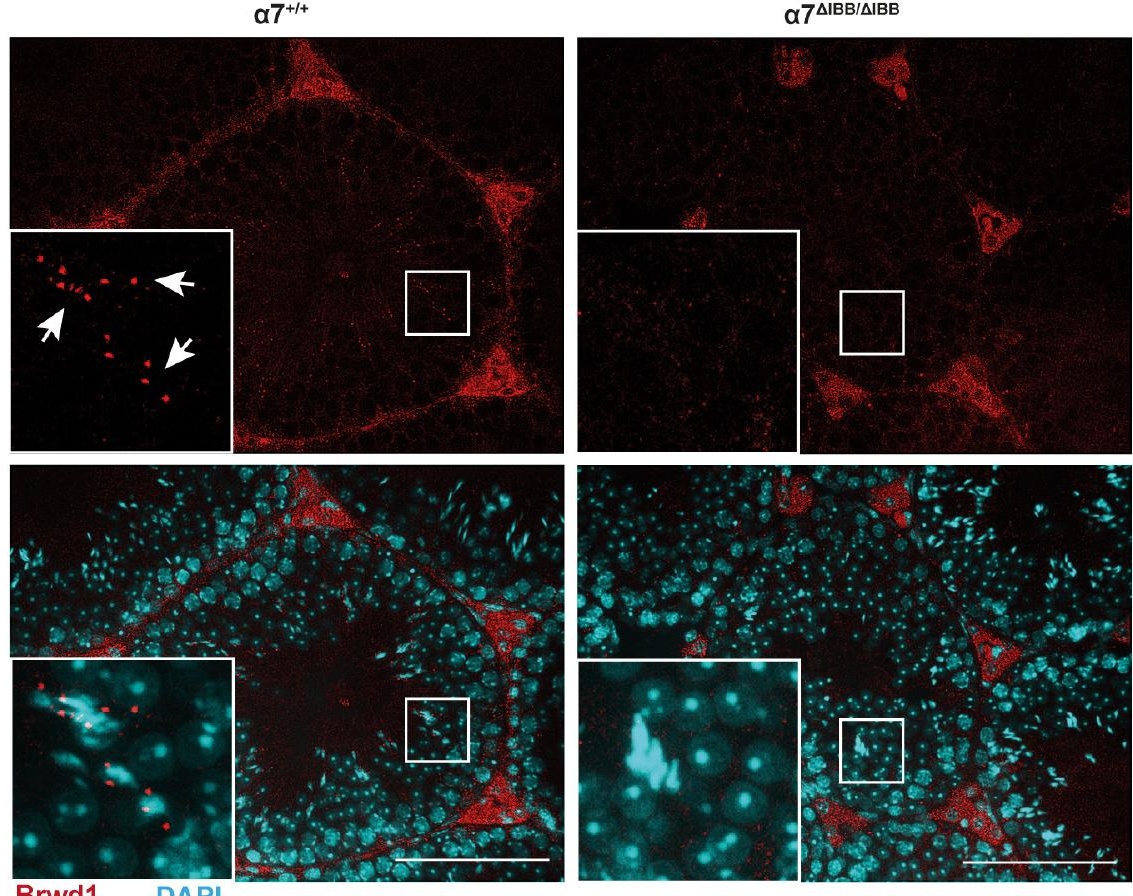

Brwd1 DAPI

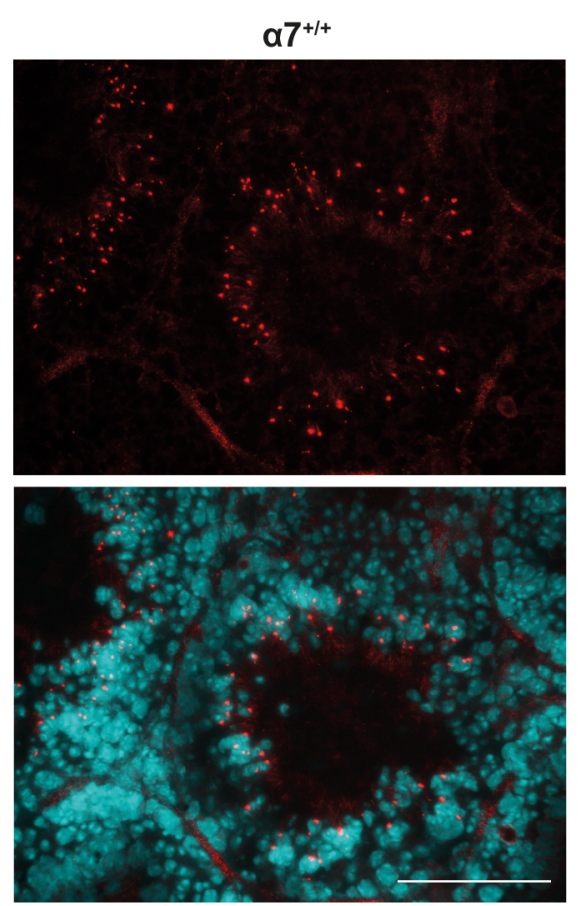

$\mathbf{a} 7^{\Delta \mathrm{IBB} / \Delta \mathrm{IBB}}$

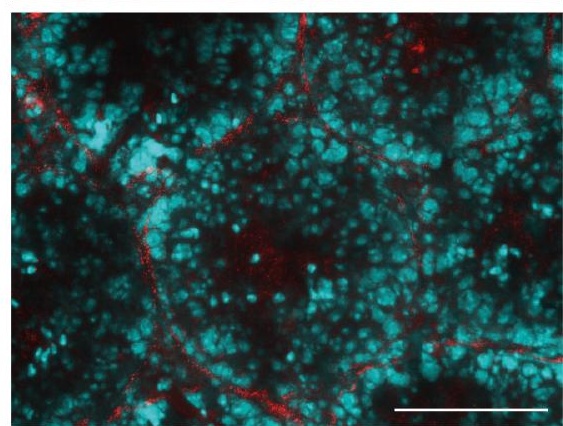

